\title{
Crescimento e desempenho motor em escolares de 7 a 15 anos provenientes de familias de baixa renda
}

\author{
Indicadores para o planejamento de programas de educação \\ física voltados à promoção da saúde
}

\author{
Adroaldo Gaya, Marcelo Cardoso, Osvaldo Siqueira e Lisiane Torres*
}

Considerando, como fazem diversos autores', que a aptidão física é um bom indicador de saúde de uma população; tendo presente que os níveis sócio-econômico podem influenciar sensivelmente nos níveis de prática desportiva e por conseqüência seus níveis de desempenho motor ${ }^{2}$ e considerando como pressuposto que se consubstancia num dos principais objetivos da educação física escolar desenvolver estratégias no âmbito da educação para a saúde $^{3}$, pretendemos, ao estudar uma população reconhecidamente de nível sócio-econômico baixo, crianças e jovens da rede municipal de ensino da cidade de Porto Alegre, oferecer a possibilidade de: (1) esboçar o perfil e monitorizar algumas variáveis relacionadas aos fenômenos d o cre s c im e n to e desenvolvimento motor; (2) possibilitar a comparação de desempenho das variáveis selecionadas entre os gêneros sexuais e entre as diversas idades; (3) analisar as curvas de desempenho de rapazes e moças identificando as zonas de pico para cada variável selecionada; (4) comparar o perfil dessas crianças e jovens com outras populações na mesma faixa etária; (5) considerando a relevância desses dados descritivos e inferenciais, sugerir indicadores de caráter didático-pedagógico capazes de orientar estratégias para o planejamento dos programas de educação fís i ca referenciados à promoção da saúde; por fim, (6) estimular a participação dos professores envolvidos com a educação física escolar para um debate sobre as sugestões oferecidas neste ensaio através da secção Temas polêmicos, colocado à disposição dos leitores da Revista Movimento publicada pela Escola de Educação Física da UFRGS.

O trabalho será dividido em duas partes. $\mathrm{Na}$ primeira, apresentamos os resultados de uma pesquisa de campo que descreve o perfil do crescimento e desempenho motor em escolares de 7 a 15 anos. Na segunda parte, que denominamos temas polêmicos, subsidiados nos dados da pesquis a apresentamos sugestões didático-pedagógicas que pretendemos se configurem em indicadores para o posterior debate. 


\section{PARTE}

Estudo do crescimento e desempenho motor em escolares de 7 a 15 anos provenientes de famílias de baixa renda do município de Porto Alegre.

\section{Método}

Configurando-se numa investigação ex-post-facto com abordagem descritiva e comparativa, com análise de corte transversal, 929 crianças (500 meninos e 429 meninas) de 7 a 15 anos, matriculadas e freqüentando regularmente as escolas da rede municipal de ensino de Porto Alegre foram selecionadas pelo procedimento do tipo aleatório por conglomerados e submetidas a medidas de peso e altura e a uma bateria de testes conforme descrito no quadro 1 .

A fidedignidade dos instrumentos de medida, inseridas na bateria de testes do projeto desporto - PRODESP $^{4}$ - foi definida pelo critério de correlação intraclasse. As correlações de Pearson entre teste e re-teste ficaram entre os intervalos de $\mathrm{r}=.86$ (teste de resistênciaforça abdominal) $)^{5}$ e 0,97 (teste de preensão manual).

Todos os testes foram realizados nas escolas da rede municipal de ensino durante as aulas de educação física, tendo sido utilizadas duas horas/aula para coleta de dados de cada turma.

Para análise dos dados, inicialmente procedeu-se ao estudo da normalidade das diferentes distribuições de valores e da eventual presença de outliers $^{6}$. Os outliers identificados, a partir da técnica de Boxplot, foram substituídos pelos valores médios da amostra. Posteriormente utilizou-se estatística descritiva (média e desvios padrão) para a configuração do perfil em cada prova, estratificada por sexo e idade. Para as análises inferenciais entre os sexos em cada faixa etária e entre as idades utilizou-se a ANÁLISE DE VARIÂNCIA do tipo ONE-WAY (ANOVA), sendo que para os testes post-hoc utilizou-se o teste de Duncan ${ }^{7}$. Para todas inferências estatísticas, adotou-se o nível de significância previamente definido em 0,05 .

\section{Resultados: Estudo descritivo e análises comparativas entre gêneros sexuais e idades}

Os resultados referentes ao peso corporal relacionados aos gêneros estão apresentados no gráfico 1 e na tabela 1 e sugerem curvas seme- lhantes. Observa-se que, entre 7 e 9 anos, rapazes e moças praticamente coincidem. No entanto, a partir dos 10 anos as moças ganham peso mais rapidamente, inclusive apresentando diferenças estatisticamente significativas entre $10 \mathrm{e}$ 12 anos (tabela 1). Todavia, este quadro começa a reverter aos 13 anos, sendo que aos 14 os rapazes superam as moças nessa variável (diferença estatisticamente significativa), sendo que, aos 15 anos, as diferenças entre os gêneros tornam a diminuir (diferença não significativa estatisticamente).

$\mathrm{O}$ início do pique de crescimento para os rapazes situa-se a partir dos 13 anos enquanto que para as moças, a partir dos 10 anos.

A ANOVA para o peso corporal entre as idades (quadro 2) para o sexo masculino aponta que não ocorrem diferenças estatisticamente significativas apenas em duas comparações e para o sexo feminino em cinco. Nos demais períodos, as crianças de mais idade apresentam valores mais altos do que as mais jovens.

Quanto ao corte transversal referente à estatura (gráfico 2), os resultados apresentam comportamentos semelhantes ao desenvolvimen-

Ouadro 1. Bateria de testes PRODESP

\begin{tabular}{|l|l}
\hline Testes & Objetivos \\
\hline Hand-gríp (em Kgf.) & Força de preensão manual \\
\hline Teste de sentar e alcançar de Wells (em cm) & $\begin{array}{l}\text { Mobilidade da coluna vertebral e estiramento dos } \\
\text { dorso-lombares e ísquios-tibiais }\end{array}$ \\
\hline Sit up 's (número de repetições em 1 min.) & Força-resistência dos músculos abdominais \\
\hline 20 metros lançados (em seg) & Velocidade de deslocamento \\
\hline Salto longitudinal sem balanço de braços $(\mathrm{cm})$ & Força explosiva de membros inferiores \\
\hline Corrida 10x5 metros & Agilidade \\
\hline Corrida de 9 minutos (distância em m) & Resistência de longa duração \\
\hline
\end{tabular}


to do peso corporal. Observase que entre os 7 e os 9 anos, embora ocorra uma tendência de maiores índices em favor dos rapazes (diferenças que não são estatisticamente significativas - tabela 1), podese afirmar que há um equilíbrio entre os gêneros sexuais. Todavia, esse quadro começa a se modificar a partir dos 10 anos, quando a curva de crescimento das moças altera seu perfil anterior, sendo que, em média, alcança os índices.dos rapazes aos 10 anos, superando-os entre os 11 e 12 anos (diferenças estatisticamente significativas — tabela 2). Já aos 13 anos, a tendência da curva de crescimento torna a se inverter. Os rapazes alcançam, em média, as moças e superam-nas a partir dos 14 anos (diferenças estatisticamente significativas — tabela 2).

Esses resultados referentes a estatura confirmam o significativo dimorfismo sexual a partir dos 10 anos até os 12 anos em prol das moças e a partir dos 14 e 15 anos em prol dos rapazes.

Rapazes e moças, nesses períodos, são, em relação ao crescimento, significativamente diferenciados, fator que certamente deverá ser considerado quando discutirmos sobre a constituição das turmas e a organização das aulas de educação física, quando referenciadas ao aprimoramento das principais capacidades motoras.

Por outro lado, os dados sugerem, em relação ao desenvolvimento da estatura, que o pique de crescimento ocorre, para as moças, entre os $10 \mathrm{e}$ 11 anos, sendo que o ritmo de crescimento diminui a partir dos 14 anos. Em relação aos
Gráfico 1

Comparação da curva de peso por sexo e idades

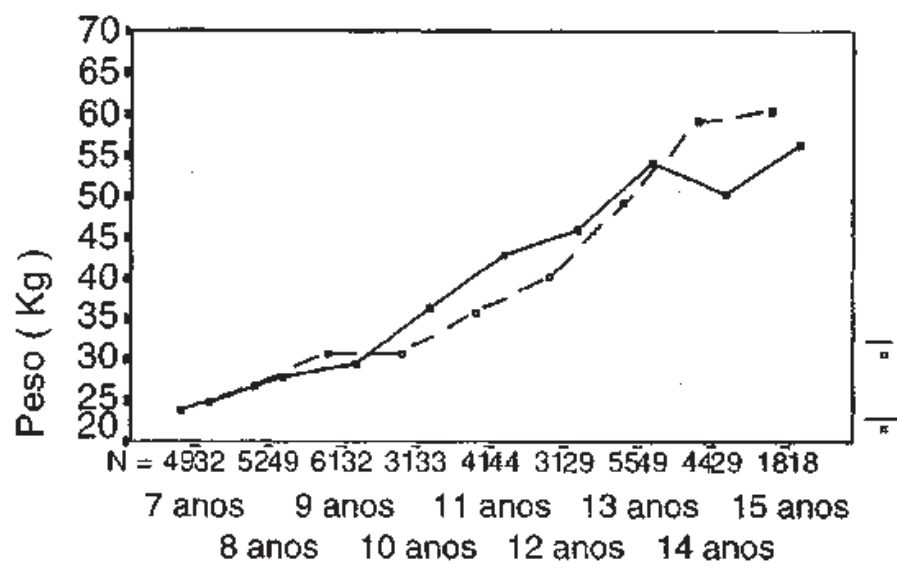

- Masculino Feminino

Idades

Tabela 1. Média e desvio padrão referente ao peso por sexo e idade.

\begin{tabular}{c|c|c|c|c}
\hline & \multicolumn{2}{|c|}{ MASCULINO } & \multicolumn{2}{c}{ FEMININO } \\
\hline IDADE & Média & DP & Média & DP \\
\hline 7 anos & 23,91 & 3,39 & 24,82 & 3,30 \\
\hline 8 anos & 26,86 & 2,69 & 27,81 & 4,67 \\
\hline 9 anos & 30,88 & 5,62 & 29,59 & 6,09 \\
\hline 10 anos & 30,87 & 3,33 & 36,30 & 7,37 \\
\hline 11 anos & 35,92 & 5,77 & $42,86^{*}$ & 6,98 \\
\hline 12 anos & 40,09 & 9,90 & $46,24^{*}$ & 10,44 \\
\hline 13 anos & 49,25 & 10,00 & 54,08 & 11,90 \\
\hline 14 anos & 59,06 & 12,28 & 50,58 & 4,53 \\
\hline 15 anos & 60,55 & 9,24 & 56,55 & 11,19 \\
\hline
\end{tabular}

(*) Indicativo de diferença estatisticamente significativa entre os sexos para $\mathrm{p}<0,05$.

Quadro Matriz de comparações múltiplas (Duncan teste) para o peso corporal

\begin{tabular}{|c|c|c|c|c|c|c|c|c|c|c|c|c|c|c|c|c|c|}
\hline \multicolumn{10}{|c|}{ Masculino } & \multicolumn{8}{|c|}{ Feminino } \\
\hline idades & $n$ & 8 & 9 & 10 & 1 & & 2 & 13 & 14 & 7 & 8 & 9 & 10 & 11 & 12 & 13 & 14 \\
\hline 8 & $*$ & & & & & & & & & ns & & & & & & & \\
\hline 9 & $*$ & $*$ & & & & & & & & $*$ & ns & & & & & & \\
\hline 10 & $*$ & $*$ & ns & & & & & & & $*$ & $*$ & * & & & & & \\
\hline 11 & * & * & $*$ & $*$ & & & & & & $*$ & $*$ & * & * & & & & \\
\hline 12 & $*$ & $*$ & $*$ & $*$ & * & & & & & $*$ & $*$ & * & $*$ & ns & & & \\
\hline 13 & $*$ & $*$ & $*$ & $*$ & $*$ & & * & & & $*$ & $*$ & $*$ & $*$ & $*$ & $*$ & & \\
\hline 14 & $*$ & $*$ & $*$ & $*$ & $*$ & * & & $*$ & & $*$ & $*$ & * & $*$ & $*$ & $*$ & ns & \\
\hline 15 & $*$ & * & * & * & * & * & * & & no & $*$ & $*$ & * & $*$ & $*$ & $*$ & $*$ & ns \\
\hline
\end{tabular}

(*) Indicativo de diferença estatisticamente significativa para $\mathrm{p}<0,05$. 
rapazes, essa fase situa-se entre tura com a de peso corporal os 12 e os 14 anos, sendo que, $(\mathrm{r}=.844)$, nota-se que a variável aos 14 anos, tal como ocorre peso apresenta um intervalo maio com as moças, diminui o ritmo de crescimento rápido, sendo que, de crescimento.

Por outro lado, quando para as moças, ocorre entre os 9 aos 13 anos e, para os rapazes, dos 10 aos 14 anos. comparamos a curva de esta-

\section{Gráfico 2}

\section{Comparação da curva de crescimento por sexo e idades}

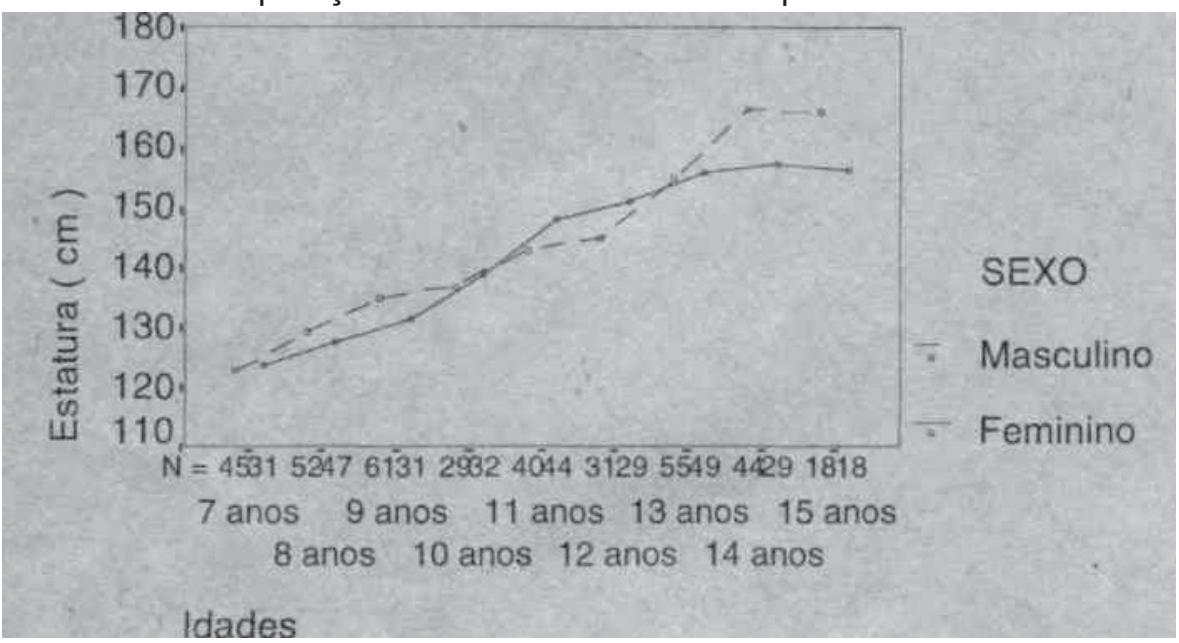

Tabela 2. Médias e desvios padrão referente a estatura por sexo e idade.

\begin{tabular}{c|c|c|c|c}
\hline & \multicolumn{2}{|c|}{ MASCULINO } & \multicolumn{2}{c}{ FEMININO } \\
\hline IDADE & Média & DP & Média & DP \\
\hline 7 anos & 122,73 & 3,99 & 123,70 & 4,32 \\
\hline 8 anos & 129,46 & 3,56 & 127,21 & 5,44 \\
\hline 9 anos & 135,22 & 4,12 & 131,67 & 5,87 \\
\hline 10 anos & 137,06 & 7,74 & 139,25 & 2,55 \\
\hline 11 anos & 143,10 & 7,90 & $148,45^{*}$ & 6,18 \\
\hline 12 anos & 145,22 & 0,88 & $151,27^{*}$ & 6,53 \\
\hline 13 anos & 155,16 & 8,48 & 156,28 & 5,32 \\
\hline 14 anos & $166,54^{*}$ & 6,93 & 157,37 & 4,67 \\
\hline 15 anos & $166,22^{*}$ & 7,31 & 156,77 & 5,67 \\
\hline
\end{tabular}

(*) Indicativo de diferença estatisticamente significativa para $\mathrm{p}<0,05$.

Qua ro 3. Matriz de comparações múltiplas (Duncan teste) para a estatura

\begin{tabular}{|c|c|c|c|c|c|c|c|c|c|c|c|c|c|c|c|c|}
\hline \multicolumn{9}{|c|}{ Masculino } & \multicolumn{8}{|c|}{ Feminino } \\
\hline idade & 7 & 8 & 9 & 10 & 11 & 12 & 13 & 14 & 7 & 8 & 9 & 10 & 11 & 12 & 13 & 14 \\
\hline 8 & \# & & & & & & & & $*$ & & & & & & & \\
\hline 9 & $*$ & $*$ & & & & & & & $*$ & $*$ & & & & & & \\
\hline 10 & $*$ & $*$ & ns & & & & & & * & * & * & & & & & \\
\hline 11 & $*$ & $*$ & $*$ & * & & & & & $*$ & \# & $*$ & $*$ & & & & \\
\hline 12 & $*$ & $*$ & * & * & ns & & & & * & $*$ & $*$ & $*$ & \# & & & \\
\hline 13 & $*$ & $*$ & $*$ & * & $*$ & * & & & * & $*$ & $*$ & \# & $*$ & $*$ & & \\
\hline 14 & $*$ & $*$ & $*$ & $*$ & $*$ & $*$ & $*$ & & $*$ & $*$ & $*$ & \# & $\%$ & $*$ & ns & \\
\hline 15 & $*$ & $*$ & $*$ & $*$ & $*$ & $*$ & $*$ & ns & $*$ & $*$ & $*$ & $*$ & $*$ & $*$ & ns & ns \\
\hline
\end{tabular}

(*) Indicativo de diferença estatisticamente significativa para $\mathrm{p}<0,05$.
A análise da variância para a estatura entre as idades (quadro 3) demonstrou que, tanto para o sexo masculino como para o feminino, somente não ocorreram diferenças estatisticamente significativa entre três comparações. Tal como ocorreu com o peso corporal, o período entre as idades implica em diferenças significativas em prol das crianças e jovens de mais idade.

Por outro lado, considerando que a Organização Mundial da Saúde (OMS) adota critérios antropomé-tricos (tais como relação altura e idade) como indicadores do estado nutricional, assumindo que o desvio da taxa normal de crescimento de uma criança reproduz deficiência nutricional, vamos encontrar nossas moças e rapazes próximos à média (no percentil 50). Desse modo, por esses critérios, pode-se inferir que nossas crianças e jovens não apresentam defasagem nutricional - o que, a princípio, põe em causa a hipótese de que alunos de classes menos privilegiadas economicamente (como é o caso dos estudantes participantes deste estudo) têm, necessariamente, comprometimentos nutricionais que podem vir a interferir na qualidade do seu processo de desenvolvimento ${ }^{8}$.

\section{Considerando a força de preensão manual como} possível variável preditora de rendimento motor referente à força máxima (gráfico 3), os resultados sugerem desempenhos semelhantes entre os gêneros sexuais até próximo aos 14 anos, embora haja uma pequena tendência de superioridade para os meninos (diferenças estatisticamente não significativas - tabela 3 ). 
Aos 14 anos, os rapazes ser consideradas em atividades Comparando os resultaapresentam melhores resultados que envolvam essa capacidade dos do teste de preensão manual (diferenças estatisticamente motora. Portanto, o trabalho com de nossos rapazes (gráficos 4) significativas) em relação às turmas heterogêneas vão exigir com amostras da Ilha da moças, o que certamente pode dos professores estratégias Madeira ${ }^{9}$ Coimbra ${ }^{10}$ (em ser explicado por fatores didático-peda-gógicas que Portugal), Maputo ${ }^{11}$ (em Morelacionados a maturação considerem adequadamente as çambique), São Caetano do Sul ${ }^{12}$ biológica.

diferenças individuais. (no Brasil), embora não

Nessa perspectiva de análise, provavelmente se possa inferir que, em atividades onde a força máxima ou sub-máxima seja exigida, as diferenças entre os gêneros, pelo menos até a puberdade masculina, não representam qualquer empecilho à constituição de turmas mistas e, nem tão pouco, parece exigir cuidados especiais quando trabalham cooperativamente moças e rapazes. Todavia, a partir dos 14 anos em média, as diferenças se tornam significativas em prol dos rapazes que, além de superarem as moças em valores absolutos, adquirem uma maior capacidade de trei-nabilidade (adaptação às cargas de treino), fatores que, necessariamente, deverão ser considerados nas atividades de educação física e treino desportivo.

Em relação ao período de pique de desempenho da força estática* as curvas sugerem o período entre os 12 e 14 anos para os rapazes e de 9 aos 12 anos para as moças, sendo que, após esses períodos, pelo menos no intervalo etário que analisamos, o desenvolvimento da força parece estabilizar-se.

Na comparação dos resultados da força de preensão manual entre as idades (quadro 4), as diferenças estatisticamente significativas predominaram. Isso significa que as diferenças na performance entre idades próximas devem

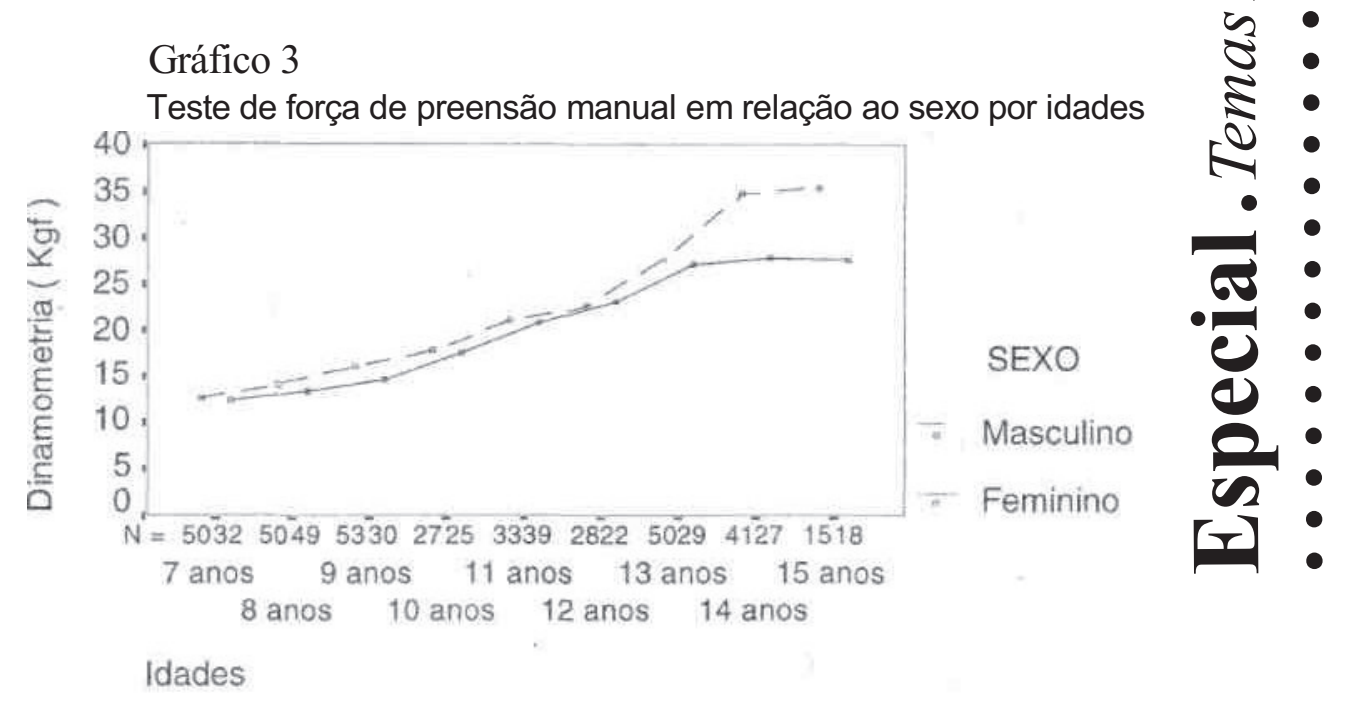

Tabela 3. Médias e desvios padrão referente ao teste de preensão manual por sexo e idade

\begin{tabular}{c|c|c|c|c}
\hline & \multicolumn{2}{|c|}{ MASCULINO } & \multicolumn{2}{c}{ FEMININO } \\
\hline IDADE & Média & DP & Média & DP \\
\hline 7 anos & 12,64 & 2,67 & 12,46 & 0,50 \\
\hline 8 anos & 14,14 & 2,92 & 13,46 & 2,70 \\
\hline 9 anos & 16,09 & 3,71 & 14,66 & 3,30 \\
\hline 10 anos & 17,77 & 3,87 & 17,64 & 3,32 \\
\hline 11 anos & 21,12 & 3,70 & 20,82 & 3,64 \\
\hline 12 anos & 22,57 & 6,54 & 23,18 & 0,66 \\
\hline 13 anos & 27,70 & 6,24 & 27,17 & 3,14 \\
\hline 14 anos & $34,75^{*}$ & 5,90 & 27,96 & 4,16 \\
\hline 15 anos & $35,46^{*}$ & 4,45 & 27,61 & 5,76 \\
\hline
\end{tabular}

(*) Indicativo de diferença estatisticamente significativa para $\mathrm{p}<0,05$.

Quadro 4. Matriz de comparações múltiplas (Duncan teste) para a força de preensão manual

\begin{tabular}{|c|c|c|c|c|c|c|c|c|c|c|c|c|c|c|c|c|}
\hline \multicolumn{9}{|c|}{ Masculino } & \multicolumn{8}{|c|}{ Feminino } \\
\hline idades & 7 & 8 & 9 & 10 & 11 & 12 & 13 & 14 & 7 & 8 & 9 & 10 & 11 & 12 & 13 & 14 \\
\hline 8 & ns & & & & & & & & ns & & & & & & & \\
\hline 9 & $*$ & $*$ & & & & & & & $*$ & ns & & & & & & \\
\hline 10 & * & $*$ & $\mathrm{~ns}$ & & & & & & $*$ & $*$ & * & & & & & \\
\hline 11 & $*$ & $*$ & $*$ & * & & & & & * & $*$ & * & $*$ & & & & \\
\hline 12 & $*$ & $*$ & $*$ & $*$ & ns & & & & * & $*$ & * & $*$ & $*$ & & & \\
\hline 13 & $*$ & $*$ & $*$ & $*$ & $*$ & $*$ & & & * & $*$ & $*$ & $*$ & $*$ & $*$ & & \\
\hline 14 & $*$ & $*$ & $*$ & $*$ & $*$ & * & $*$ & & * & * & * & $*$ & $*$ & $*$ & ns & \\
\hline 15 & $*$ & $*$ & * & $*$ & $*$ & $*$ & $*$ & ns & * & $*$ & $*$ & $*$ & $*$ & $*$ & $\mathrm{~ns}$ & ns \\
\hline
\end{tabular}

(*) Indicativo de diferença estatisticamente significativa para $\mathrm{p}<0,05$. 
Gráfico 4

\section{Perfil de alguns estudos sobre a dinamometria}

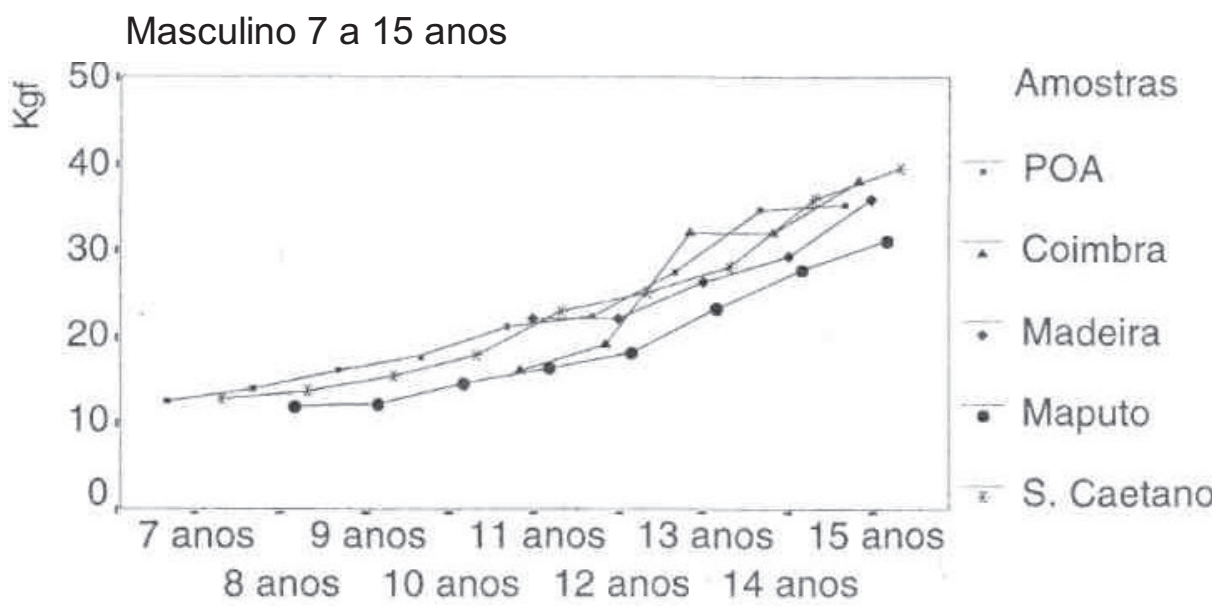

Idades

Gráfico 5

Perfil de alguns estudos sobre a dinamometria Feminino 7 a 15 anos

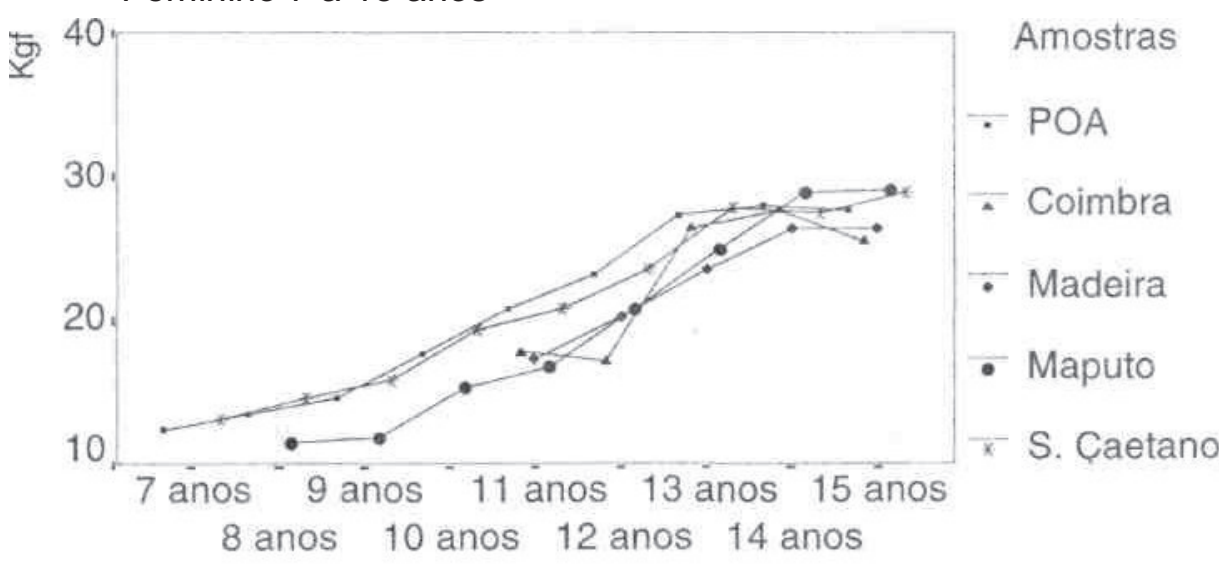

Idades

\begin{tabular}{|c|c|c|c|c|c|c|c|c|c|c|c|c|c|c|c|c|}
\hline \multicolumn{2}{|c|}{ Quadro } & \multicolumn{4}{|c|}{ Matriz de } & \multicolumn{5}{|c|}{ múltiplas (Duncan teste) } & \multicolumn{6}{|c|}{ a flexibilidade } \\
\hline \multicolumn{9}{|c|}{ Masculino } & \multicolumn{8}{|c|}{ Feminino } \\
\hline idade & $n$ & 8 & 9 & 10 & 11 & 12 & 13 & 14 & 7 & 8 & 9 & 10 & 11 & 12 & 13 & 14 \\
\hline 8 & ns & & & & & & & & ns & & & & & & & \\
\hline 9 & $*$ & ns & & & & & & & ns & ns & & & & & & \\
\hline 10 & $*$ & \# & $*$ & & & & & & ns & $\mathrm{ns}$ & ns & & & & & \\
\hline 11 & $*$ & $*$ & ns & $\mathrm{ns}$ & & & & & ns & $\mathrm{ns}$ & ns & ns & & & & \\
\hline 12 & ns & $*$ & ns & * & $*$ & & & & ns & ns & ns & ns & ns & & & \\
\hline 13 & $*$ & ns & ns & ns & ns & * & & & $*$ & * & * & * & \# & * & & \\
\hline 14 & * & ns & ns & * & ns & ns & ns & & ns & * & ns & ns & ns & * & ns & \\
\hline 15 & ns & $\mathrm{ns}$ & ns & * & * & ns & * & ns & * & $*$ & $*$ & $*$ & $*$ & $*$ & ns & ns \\
\hline
\end{tabular}

(*) Indicativo de diferença estatisticamente significativa para $\mathrm{p}<0,05$. rações entre os 7 e os 10 anos para todas as amostras, interessa-nos referir que os resultados de nossos rapazes são próximos aos de São Caetano do Sul e da Ilha da Madeira, até os 12 anos são superiores e após equivalem-se aos de Coimbra, são superiores em média aos de Moçambique e, embora não conste no gráfico para evitar a superposição de curvas, situam-se em condições semelhantes aos rapazes da cidade do Porto ${ }^{13}$, dos Açores ${ }^{14}$ e, no período entre os 13 e 14 anos, aproximam-se dos rapazes holandeses ${ }^{15}$.

Em relação às moças (quadro 5), ds dados são mais otimistas na medida em que nossa amostra tende a superar as moças de Maputo, da Ilha da Madeira, Coimbra (até aos 12 anos), praticamente se equipara a amostra de São Caetano do Sul (gráfico 5), da cidade do Porto e se aproxima das moças holandesas (não representadas no gráfico).

Se considerarmos que as amostras de Coimbra e do Porto são constituídas por rapazes e moças participantes do desporto escolar; se consideramos que a amostra de São Caetano do Sul não é estratificada por nível sócio-econômico e se considerarmos os níveis de qualidade de vida dos holandeses, os resultados, pelo menos no que se refere à força máxima, parecem refutar as hipóteses e especulações que, muito freqüentemente, sugerem que crianças oriundas de populações de baixo nível sócio-econômico tendem a apresentar índices inferiores em testes de aptidão física. Sobre o aspecto pedagógico, essas constatações são muito importantes, isto porque, podem colaborar para desmi- 
tificar discursos correntes em nossa realidade que pretendem, em nome de uma pretensa carência estrutural protéica atribuída genericamente às populações mais pobres, destituir as aulas de educação física de atividades fisicamente mais exigentes.

Quanto aos resultados da variável flexibilidade, medida através da mobilidade da coluna vertebral pelo teste de sentar-alcançar de Wells"' (gráfico 6), chama a atenção, primeiramente, a estabilidade da performance ao longo do período etário analisado. Embora ocorram alterações nas curvas aos 10, 14 e 15 anos em prol das meninas (diferenças estatisticamente significativas - tabela 4), o que se observa é que as diferenças no desempenho no espaço entre os 7 e 15 anos em ambos os sexos não é significativa. Esse indicador sugere, embora considerando as limitações de um estudo de corte transversal, que possivelmente essa capacidade motora, tão importante no âmbito da saúde, não é adequadamente trabalhada nas aulas de educação física e nem tão pouco é exercitada nas atividades cotidianas a ponto de proporcionar um desenvolvimento compatível com os estágios de crescimento e desenvolvimento somato-motor.

Como se pode observar pelo gráfico 6, até os 9 anos há um equilíbrio nos resultados de flexibilidade entre os gêneros. A partir dos 9 anos, os rapazes diminuem seus índices significativamente em relação as moças. Esse fenômeno perdura até os 11 anos, quando então os rapazes retornam aos índices de desempenho que haviam atingido na idade de 9 anos, permanecendo, nesse platô, com pequenas alterações nos resultados, até os 15 anos. A curva das moças apresenta uma leve inflexão entre 11 e 12 anos, em seguida torna a se elevar de forma importante até os 13 anos (ocorrendo, nessa fase, diferenças estatisticamente significativas em relação aos rapazes) e permanecendo mais ou menos constante até os 15 anos.

No que tange à flexibilidade, em se tratando de

identificar os períodos de pico, pela linearidade apresentada na curva do sexo masculino ao longo do período analisado, não é possível extrair qualquer inferência minimamente confiável. Já em relação as moças, possivelmente se possa conjeturar que a aproximação do período pubertário influencia positivamente os índices de flexibilidade, desse modo, demarcando esse período, provavelmente, como sensível ao desenvolvimento dessa capacidade motora.

\section{Gráfico 6 \\ Teste de mobilidade da coluna vertebral em relação ao sexo por idades}

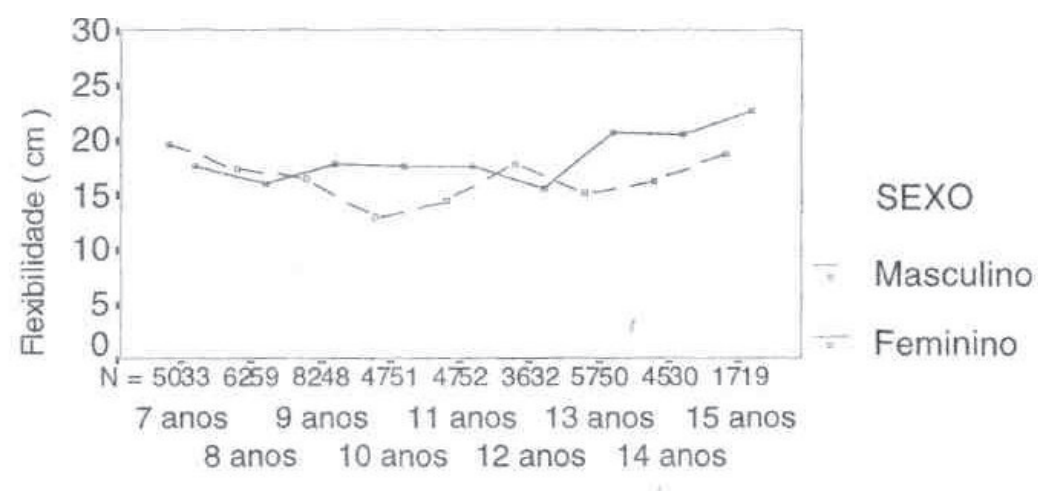

Idades

Tabela 4. Médias e desvios padrão referente ao teste de flexibilidade por sexo e idade

\begin{tabular}{c|c|c|c|c}
\hline & \multicolumn{2}{|c|}{ MASCULINO } & \multicolumn{2}{c}{ FEMININO } \\
\hline IDADE & Média & DP & Média & DP \\
\hline 7 anos & 19,56 & 4,95 & 17,69 & 5,65 \\
\hline 8 anos & 17,37 & 5,35 & 16,18 & 5,52 \\
\hline 9 anos & 16,53 & 5,79 & 17,83 & 5,16 \\
\hline 10 anos & 12,93 & 6,49 & $17,54^{*}$ & 1,25 \\
\hline 11 anos & 14,48 & 6,27 & 17,67 & 6,27 \\
\hline 12 anos & 17,86 & 3,46 & 15,68 & 5,61 \\
\hline 13 anos & 15,14 & 7,05 & $20,72^{*}$ & 7,11 \\
\hline 14 anos & 16,31 & 5,93 & 20,36 & 6,20 \\
\hline 15 anos & 18,76 & 4,52 & 22,63 & 6,84 \\
\hline
\end{tabular}

(*) Indicativo de diferença estatisticamente significativa para $p<0,05$. 
Considerando as diversas faixas etárias (quadro 5), observamos que predominam as comparações onde não ocorrem diferenças estatisticamente significativas. Entretanto, para os rapazes, onde as diferenças foram estatisticamente significativas, ocorreram duas situações: (a) as idades mais baixas superaram as mais elevadas no períodos entre 7 , 8 e 9 anos quando comparados com 10 e 11 anos e (b) as idades mais altas superam as mais baixas, sendo os 10 anos $<12,14,15$ e os $11<13,14$ anos. Entretanto, essas diferenças se devem principalmente a um decréscimo da flexibilidade no período entre 10 e 11 anos. Para o sexo feminino, os resultados apresentam-se mais homogênios. Cabe ressaltar que as diferenças quando ocorreram de forma significativa foram principalmente por conseqüência dos índices superiores atingidos pelas meninas aos $13 \mathrm{e}$ 15 anos.
O comportamento heterogênio dos dados de nosso estudo parece confirmar a pouca relação da flexibilidade com o sexo e idade referida por Cooper (1991). Todavia, somos de opinião que esse fenômeno é conseqüência da pouca atenção que é dispensada ao desenvolvimento da flexibilidade nos programas de educação física. Todos sabemos que a flexibilidade, independentemente de sexo e idade, exige treinamento específico e contínuo. No entanto, não obstante a relevância dessa variável no quadro de aptidão física relacionada à saúde, as evidências sugerem que a flexibilidade não vem sendo devidamente trabalhada.

Para a análise comparativa entre diversas realidades em relação à mobilidade da coluna vertebral medida através do sit and reach, o gráfico 7 contrapõe nossa amostra de rapazes com as de Londrina $^{17}$ (Brasil); Madei-

\section{Gráfico 7}

\section{Perfil de alguns estudos sobre a flexibilidade}

\section{Masculino 7 a 15 anos}

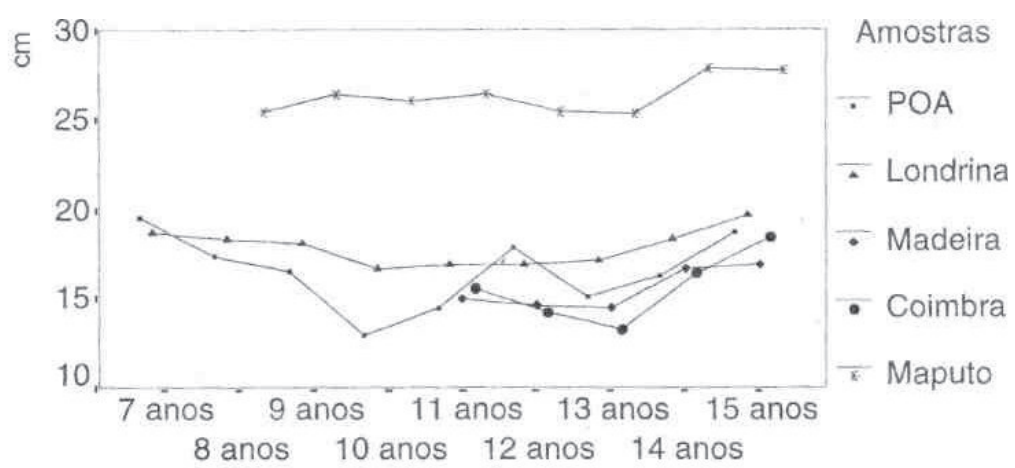

Idades $\mathrm{ra}^{18}$ e Coimbra $^{19}$ (Portugal); eMaputo $^{20}$ (Moçambique), e, embora não conste no gráfico, consideraremos dados amostrais dos EUA ${ }^{21}$, Holanda ${ }^{22}$, Bélgica ${ }^{23}$ e cidade do Porto $^{24}$.

Ao observarmos com cuidado os resultados, deparamo-nos com uma realidade bastante desfavorável para os nossos rapazes. Com exceção dos 7 e 8 anos, onde estamos próximos aos de Londrina, nas idades seguintes nossos índices caem significativamente até os 10 anos, recupera a partir dos 11 , mas, no entanto, permanecem muito distante dos índices dos paranaenses. A partir dos 11 anos, quando as referências para a comparação são mais numerosas, vamos verificar que os nossos rapazes, em média, equivalem-se aos da Ilha da Madeira e de Coimbra (que, por sua vez, equivalem-se às amostras do Porto não apresentadas no gráfico); não obstante, ficando bem afastados dos meninos de Maputo e dos EUA, Holanda e Bélgica (os três últimos também não representados no gráfico).

Em relação ao gênero feminino (gráfico 8), a discrepância que observamos entre os rapazes de Porto Alegre e Londrina não ocorre. Como se pode observar, nossos resultados, embora com a tendência de apresentarem-se mais baixos que as moças paranaenses, todavia situam-se muito próximo a esses. Da mesma forma, nossa amostra se eqüivale à da Ilha da Madeira, sendo, no entanto, inferior a amostra de Coimbra, do Porto e significativamente inferior 


\section{Gráfico 8}

Perfil de alguns estudos sobre a flexibilidade

Feminino 7 a 15 anos

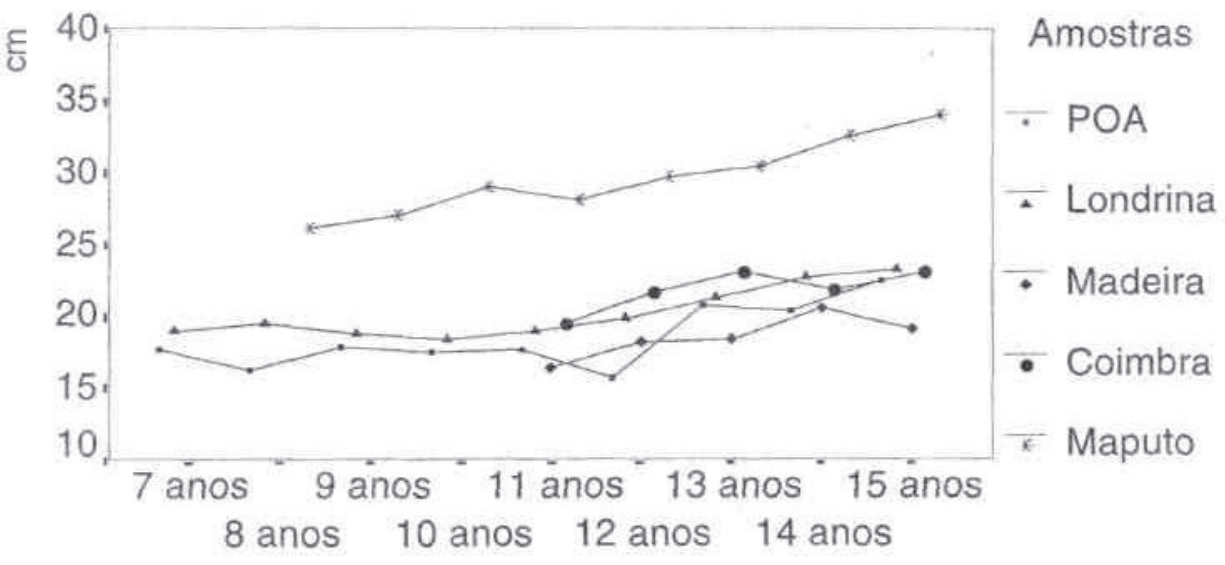

Idades

às amostras de Maputo e dos EUA (sendo que Porto e EUA não estão representadas no gráfico).

Comparando os resultados de nossa amostra com os resultados padronizados para testes de aptidão física relacionados com a saúde proposta por Cooper (1992) cujo índice de flexibilidade é $17 \mathrm{~cm}^{25}$, nossos rapazes estão abaixo dos índices aos 9, 10, 11, 13 e 14 anos e as moças aos 8 e aos 12 anos.

Parece-nos evidente, perante os dados apresentados, que, em nossos programas de educação física, necessitamos dedicar maior atenção à componente flexibilidade. Pela sua importância no perfil da aptidão física referenciada à saúde, pela exigência de trabalhos específicos para o seu aprimoramento, sem dúvida se torna premente uma atuação nesse sentido.

O gráfico 9 apresenta os resultados do teste de força-resistência abdominal. Observa-se índices estatisticamente significativos entre os 7 e 8 anos em prol dos rapazes, posteriormente entre os 9 e 10 anos há um equilíbrio na performance e, novamente, a partir dos 11 anos observarmos a tendência de níveis superiores de desempenho para os rapazes (com diferenças estatisticamente significativas aos $11,12,13$ e 14 anos - tabela 5), fenômeno que ocorre muito mais pela diminuição dos índices das moças que propriamente pelo progresso dos rapazes.
Por outro lado, é de salientar o fato de que, tal como ocorreu com a flexibilidade, é pouco relevante o desenvolvimento da força-resistência abdominal quando comparamos o período compreendido entre os 7 aos 15 anos. Essa constatação nos leva a crer que essa propriedade motora também não está sendo adequadamente atendida nas aulas de educação física e, da mesma forma, as atividades cotidianas, per se, parecem não ser suficientes para desenvolvê-las.

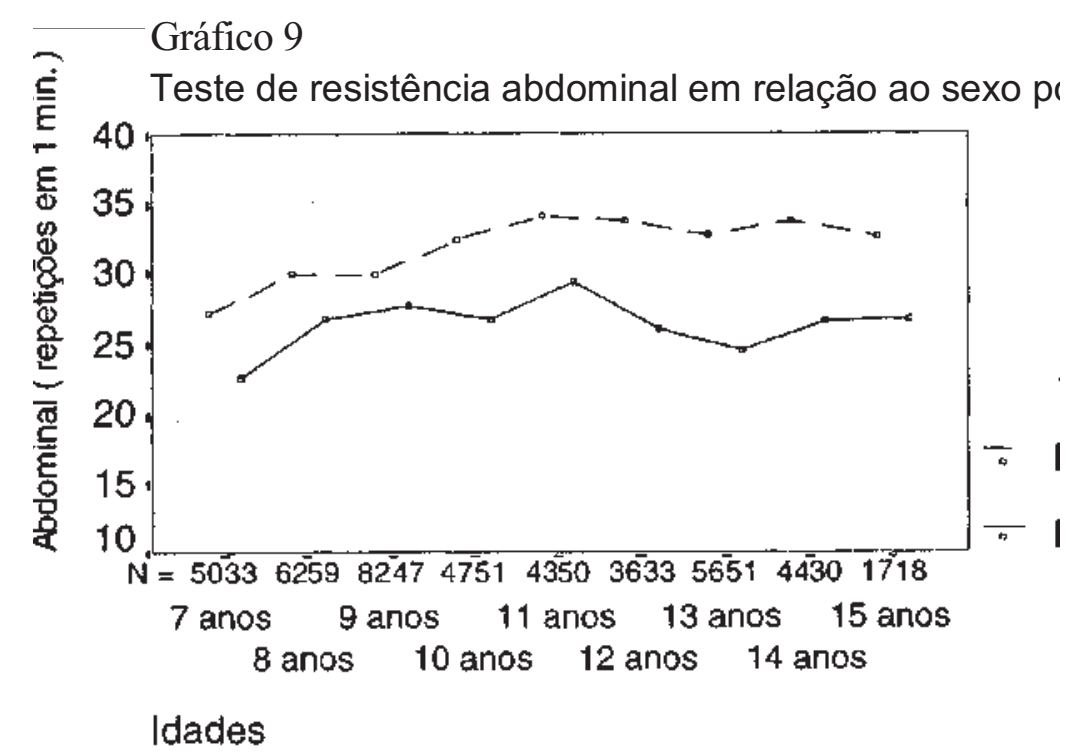


Os dados sobre a forçaresistência abdominal parecem sugerir que possa ocorrer uma zona de pique de crescimento para os rapazes entre os 9 e 11 anos, não sendo, todavia, possível identificar tal ocorrência na curva de desempenho das moças.

O quadro 6 apresenta os resultados da matriz de comparações múltiplas entre as idades para ambos os sexos na variável força-resistência abdominal. Como se pode observar, para o sexo masculino, aos 7 anos, o desempenho é menor quando comparado com todas as demais idades, aos $11 \mathrm{e}$ 12 anos ocorrem os melhores índices, fatores que explicam o perfil expresso ao lado esquerdo do quadro 6.
Para o sexo feminino, os resultados da matriz de comparações sugerem uma evidente homogeneidade de performance. Como podemos observar, somente em três comparações ocorrem diferenças estatisticamente significativas.

Esses dados permitem inferir que as pequenas diferenças de performance que ocorrem entre as idades são decorrentes de níveis relativamente baixos de desempenho nessa capacidade motora.

Por outro lado, comparando nosso resultados com os índices limites propostos por Cooper como indicadores de aptidão para a saúde, nossos rapazes têm resultados infe-

Tabela 5. Médias e desvios padrão referentes ao teste abdominal por sexo e idade.

\begin{tabular}{c|c|c|c|c}
\hline & \multicolumn{2}{|c|}{ MASCULINO } & \multicolumn{2}{c}{ FEMININO } \\
\hline IDADE & Média & DP & Média & DP \\
\hline 7 anos & 27,20 & 5,39 & 22,60 & 9,84 \\
\hline 8 anos & 29,98 & 7,16 & 26,76 & 6,33 \\
\hline 9 anos & 30,01 & 8,43 & 27,65 & 5,77 \\
\hline 10 anos & $32,40^{*}$ & 7,93 & 26,84 & 6,92 \\
\hline 11 anos & 34,11 & 7,66 & 29,36 & 16,16 \\
\hline 12 anos & $33,72^{*}$ & 5,76 & 25,93 & 7,88 \\
\hline 13 anos & 32,69 & 5,37 & 24,54 & 7,36 \\
\hline 14 anos & $33,72^{*}$ & 7,73 & 26,53 & 5,36 \\
\hline 15 anos & 32,58 & 8,38 & 26,77 & 7,19 \\
\hline
\end{tabular}

(*) Indicativo de diferença estatisticamente significativa para $\mathrm{p}<0,05$.

Quadro Matriz de comparações > múltiplas (Duncan teste) para a abd imin

\begin{tabular}{|c|c|c|c|c|c|c|c|c|c|c|c|c|c|c|c|c|}
\hline \multicolumn{9}{|c|}{ Masculino } & \multicolumn{8}{|c|}{ Feminino } \\
\hline idade & ${ }^{H}$ & 8 & 9 & 10 & 11 & 12 & 13 & 14 & 7 & 8 & 9 & 10 & 11 & 12 & 13 & 14 \\
\hline 8 & $*$ & & & & & & & & ns & & & & & & & \\
\hline 9 & $*$ & ns & & & & & & & $*$ & ns & & & & & & \\
\hline 10 & $*$ & ns & ns & & & & & & ns & ns & ns & & & & & \\
\hline 11 & $*$ & $*$ & $*$ & ns & & & & & $*$ & ns & ns & ns & & & & \\
\hline 12 & * & $*$ & $*$ & ns & ns & & & & ns & ns & ns & ns & ns & & & \\
\hline 13 & * & ns & ns & ns & ns & $*$ & & & ns & ns & ns & ns & * & ns & & \\
\hline 14 & * & $*$ & $*$ & $\mathrm{~ns}$ & ns & $\mathrm{ns}$ & $\mathrm{ns}$ & & ns & ns & ns & ns & ns & ns & ns & \\
\hline 15 & $*$ & ns & ns & ns & ns & ns & ns & ns & ns & ns & ns & ns & ns & ns & ns & $\mathrm{ns}$ \\
\hline
\end{tabular}

(*) Indicativo de diferença estatisticamente significativa para $p<0,05$. (

ns) Indicativo para diferença não significativa

riores entre os 9 e 15 anos, enquanto nossas moças, a partir dos 12 anos. Conseqüentemente, pode-se conjecturar que os professores de educação física em suas aulas, assim como ocorreu com a flexibilidade, não têm considerado devidamente o aprimoramento da força-resistência abdominal. Essa evidência é preocupante na medida que, no quadro da aptidão física referenciada à saúde, todos sabemos da importância dessa variável, principalmente se considerarmos as questões inerentes aos aspectos posturais que hoje, sem dúvida, constituem-se num preocupante problema de saúde pública, uma vez que são freqüentes as ocorrências de desvios posturais em populações cada vez mais jovens.

O gráfico 10 apresenta o desempenho relativo dos rapazes de Porto Alegre em relação a outras amostras no teste de resistência-força abdominal. Observa-se que nossos rapazes situam-se próximos aos de Londrina e da Ilha da Madeira, com uma tendência de maiores índices até aos 13 anos quando, então, a tendência se inverte. Todavia, se estamos com desempenho superior aos rapazes de Moçambique, estamos significativamente inferiorizados em relação aos rapazes de Coimbra.

Em relação às moças, até os 11 anos nossa amostra de Porto Alegre equipara-se às paranaenses de Londrina, posteriormente nosso desempenho se apresenta inferior até os 13 anos quando novamente volta a se equiparar a partir dos 12 . Nesse período, onde ocorre um decréscimo no desempenho das moças de Porto Alegre, ficamos inferio- 
rizados em relação às da $\mathrm{Ma}$ deira. Tal como ocorreu com os rapazes, nossa amostra ficou com índices superiores de desempenho em relação aos moçambicanos e significativamente inferiores quando comparados com as moças de Coimbra.

O gráfico 12 apresenta os resultados do teste de salto em distância sem balanço de braços, teste que avalia a capacidade de força explosiva de membros inferiores.

Ao compararmos com o gráfico 3, referente à força de preensão manual, podemos observar algumas semelhanças no comportamento das curvas de performance: (1) vamos perceber que os piques de crescimento ocorrem na mesma idade tanto para as meninas (a partir dos 9 até os 11 anos) como para os meninos (notadamente a partir dos 12 até os 14 anos). (2) As curvas de pique de desenvolvimento da força são bem mais acentuadas para os meninos do que para as meninas.

Por outro lado, diferentemente do que sucedeu com a força de preensão manual, onde ocorreu um equilíbrio na performance até os 13 anos, na força explosiva de membros inferiores a performance é, na maioria do período etário investigado, com exceção dos 7 , 8 e 10 anos, significativamente superior em prol dos meninos.

Como conseqüência desses resultados, torna-se evidente que na organização das aulas de educação física, em cujo conteúdo planejam-se atividades que considerem essa capacidade motora, a im-
Gráfico 10

Perfil de alguns estudos sobre a resistência abdominal

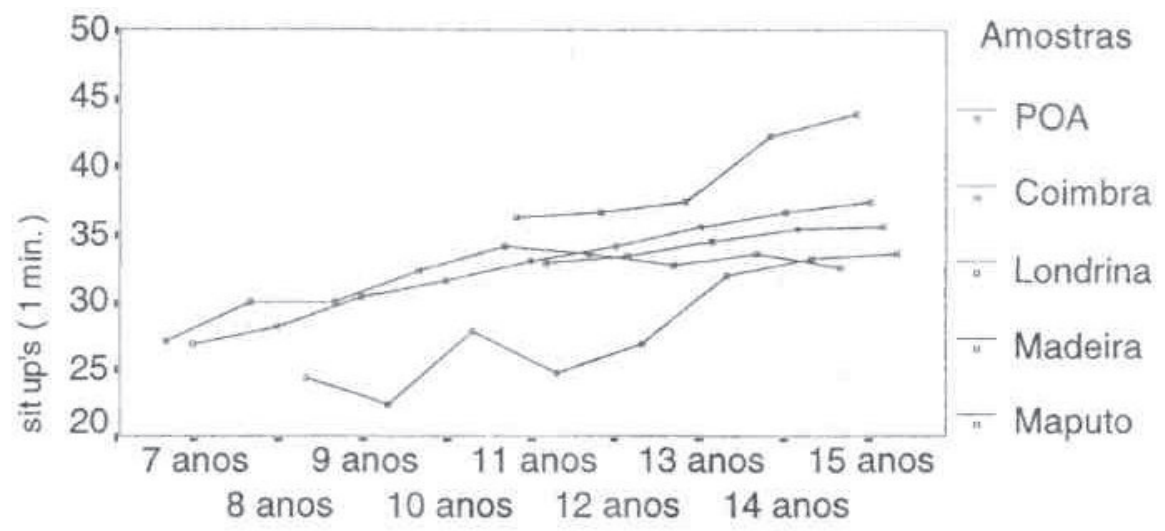

Idades

Masculino 7 a15 anos

Gráfico 11

Perfil de alguns estudos sobre a resistência abdominal

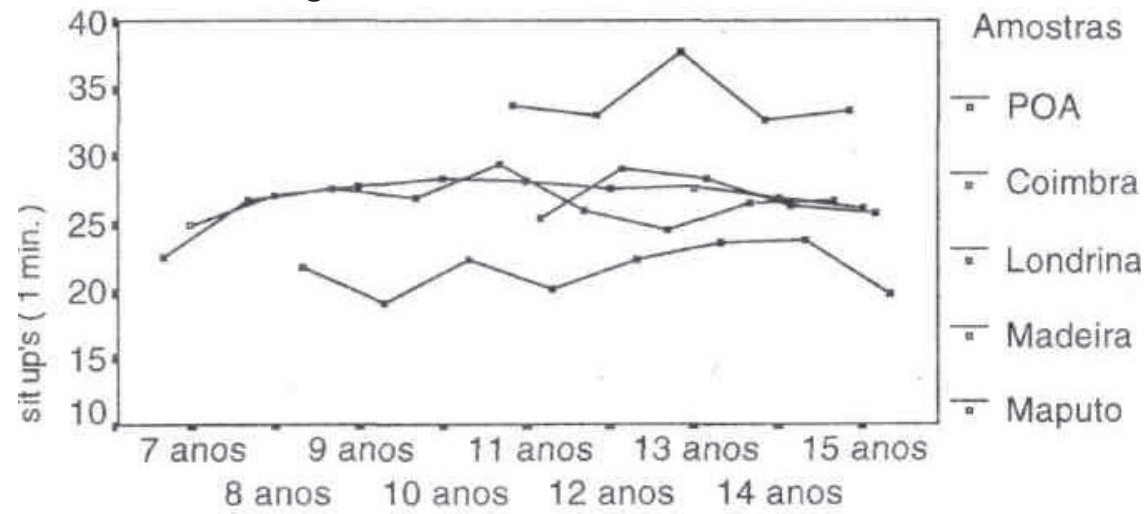

Idades

Feminino 7 a 15 anos

Gráfico 12

Teste de força explosiva de membros inferiores

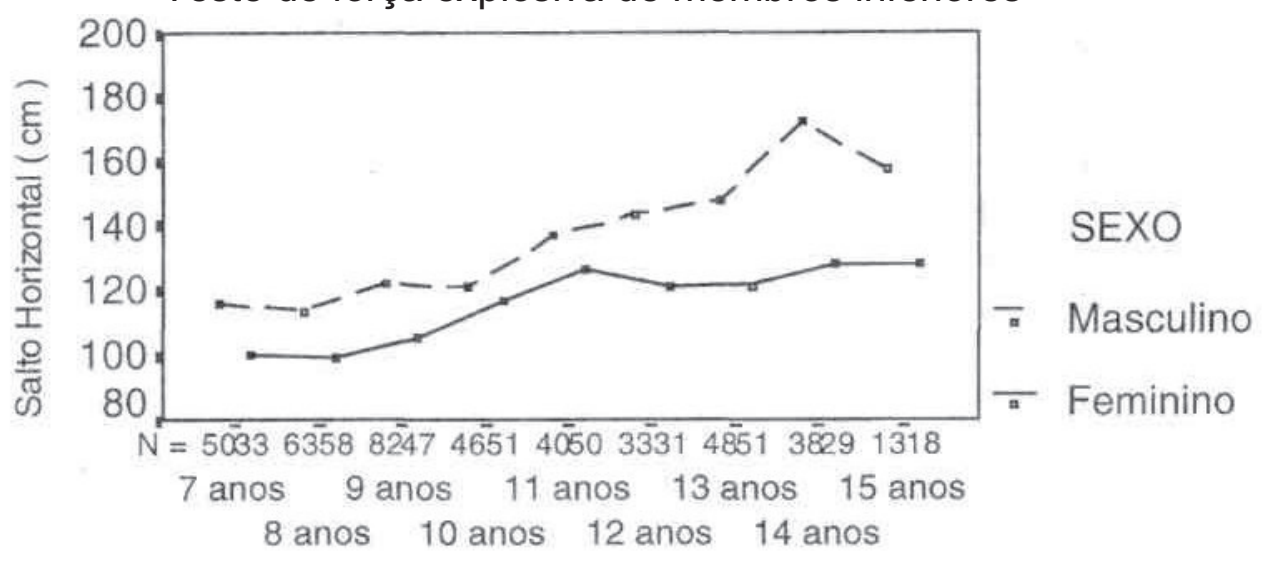

Idades

em relação ao sexo por idades 
posição de cuidados especiais apazes, o quadro 7 nos aponta entre rapazes e moças se faz para a possibilidade de um necessário.

pelos meninos entre 7 a 10

Em relação à compara- anos. No entanto, essa homoção entre as idades para os geneidade não é verificada

Tabela 6. Médias e desvios padrão referente ao teste salto horizontal por sexo e idade.

\begin{tabular}{c|c|c|c|c}
\hline & \multicolumn{2}{|c|}{ MASCULINO } & \multicolumn{2}{c}{ FEMININO } \\
\hline IDADE & Média & DP & Média & DP \\
\hline 7 anos & $116,58^{*}$ & 18,70 & 100,30 & 20,17 \\
\hline 8 anos & $114,12^{*}$ & 15,37 & 100,01 & 19,62 \\
\hline 9 anos & $122,41^{*}$ & 4,22 & 105,48 & 14,75 \\
\hline 10 anos & 121,69 & 1,39 & 116,88 & 19,23 \\
\hline 11 anos & 137,00 & 18,55 & 126,82 & 20,46 \\
\hline 12 anos & $143,93^{*}$ & 24,21 & 121,58 & 20,77 \\
\hline 13 anos & $148,10^{*}$ & 27,56 & 122,03 & 20,63 \\
\hline 14 anos & $172,34^{*}$ & 32,63 & 128,82 & 18,05 \\
\hline 15 anos & $157,30^{*}$ & 31,30 & 128,66 & 31,13 \\
\hline
\end{tabular}

( $^{*}$ ) Indicativo de diferença estatisticamente significativa para $\mathrm{p}<0,05$.

Quadro Matr zde imp raçõe mú tipias ^Duncan para $\quad$ o salto hori ontal

\begin{tabular}{|ccccccccc|cccccccc|}
\hline \multicolumn{10}{c|}{ Ma scul 10} & \multicolumn{1}{c|}{ Femi nino } & & \\
\hline idade & $n$ & 8 & 9 & 10 & 11 & 12 & 13 & 14 & 7 & 8 & 9 & 10 & 11 & 12 & 13 & 14 \\
8 & $\mathrm{~ns}$ & & & & & & & & ns & & & & & & & \\
9 & $\mathrm{~ns}$ & $*$ & & & & & & & $\mathrm{~ns}$ & $\mathrm{~ns}$ & & & & & & \\
10 & $\mathrm{~ns}$ & $\mathrm{~ns}$ & $\mathrm{~ns}$ & & & & & & $*$ & $*$ & $*$ & & & & & \\
11 & $*$ & $*$ & $*$ & $*$ & & & & & $*$ & $*$ & $*$ & $*$ & & & & \\
12 & $*$ & $*$ & $*$ & $*$ & $\mathrm{~ns}$ & & & & $*$ & $*$ & $*$ & $\mathrm{~ns}$ & $\mathrm{~ns}$ & & & \\
13 & $*$ & $*$ & $*$ & $*$ & $*$ & $\mathrm{~ns}$ & & & $*$ & $*$ & $*$ & $\mathrm{~ns}$ & $\mathrm{~ns}$ & $\mathrm{~ns}$ & & \\
14 & $*$ & $*$ & $*$ & $*$ & $*$ & $*$ & $*$ & & $*$ & $*$ & $*$ & $*$ & $\mathrm{~ns}$ & $\mathrm{~ns}$ & $\mathrm{~ns}$ & \\
15 & $*$ & $*$ & $*$ & $*$ & $*$ & $*$ & $\mathrm{~ns}$ & $*$ & $*$ & $*$ & $*$ & $*$ & $\mathrm{~ns}$ & $\mathrm{~ns}$ & $\mathrm{~ns}$ & $\mathrm{~ns}$ \\
\hline
\end{tabular}

(*) Indicativo de diferença estatisticamente significativa para $p<0,05$.

(ns) Indicativo para diferença não significativa

\section{Gráfico 13}

Perfil de alguns estudos sobre salto em extensão

Masculino 7 a 15 anos

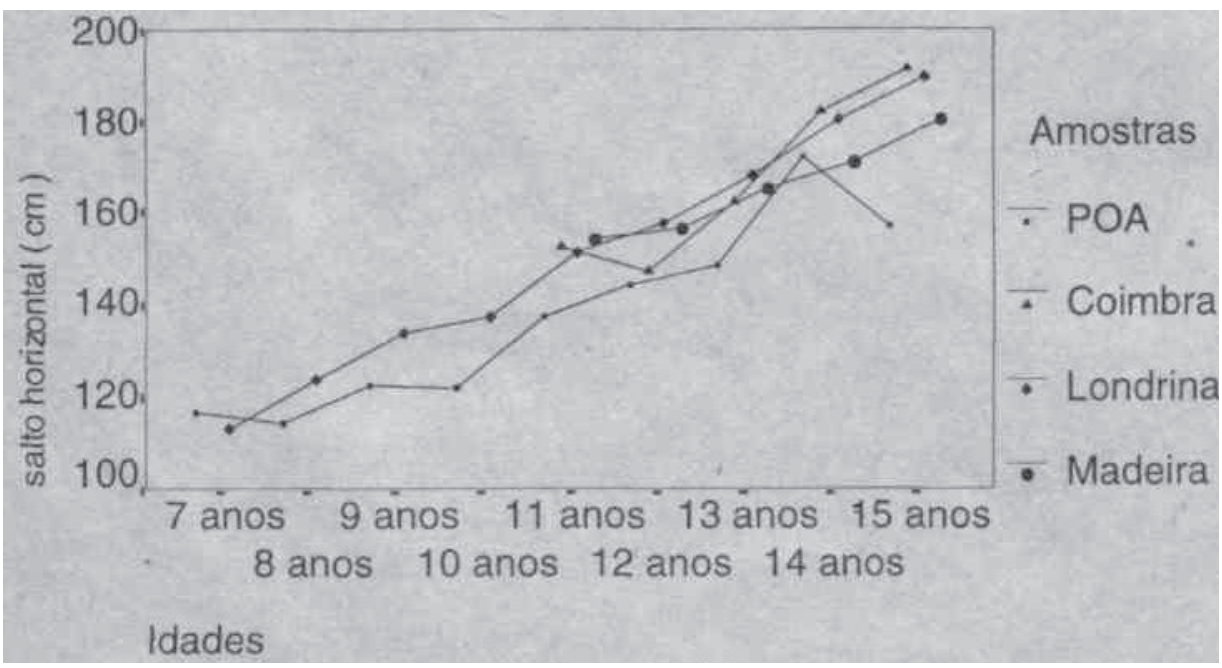

nos períodos seguintes, com exceção a fases pontuais entre 11 e 12,12 e 13 e 13 e 15 onde não ocorrem diferenças significativas.Todavia, cabe ressaltar que um pique de performance, verificado aos 14 anos, faz com que, nessa idade, os resultados sejam superiores aos dos 15 anos.

Para as moças, a matriz de comparações múltiplas se apresenta de forma a sugerir a presença de um grupo homogênio entre 7 e 8 anos, posteriormente devemos considerar as diferenças significativas que ocorrem entre os 9, 10 e 11 anos, para novamente considerarmos equivalentes as performances entre 12 a 15 anos.

Portanto, para além das preocupações em relação ao gênero sexual para as atividades que envolvam a força explosiva, alguns outros cuidados devem ser estabelecidos quando são propostas atividades em conjunto para turmas compostas por alunos de idades heterogêneas.

O gráfico 13 , que demonstra as tendências de desempenho da força explosiva de membros inferiores medida através do salto horizontal entre amostras diversas, sugere que nossos rapazes, a partir dos 8 anos e excetuando os 14 anos, encontram-se em níveis de performance inferiores aos rapazes de Londrina, Coimbra e Ilha da Madeira.

Considerando o gráfico 14 , podemos perceber que, em relação às moças, a desvantagem das porto-alegrenses em comparação com as moças de Coimbra, Londrina e Madeira é ainda mais significativa do que foram a dos rapazes fren- 
te aos conjêneres desses mesmos municípios. Observa-se que, com exceção à idade de 8 anos, quando as moças de Porto Alegre se aproximam das moças de Londrina, nas demais idades elas apresentam sempre índices inferiores, diferenças que aumentam ainda mais a partir dos 12 anos de idade.

Quanto aos resultados do teste de agilidade, o gráfico 15 apresenta para as moças uma ligeira inflexão entre os 8 e 9 anos e para os rapazes entre os 7 e 8 anos. A partir dessas idades, ocorre um aumento progressivo na agilidade até os 12 anos para ambos os gêneros sexuais quando ocorre uma nova inflexão da curva. Ressaltase um provável pique de performance para os rapazes aos 13 anos. Todavia, não é possível detectar pelos dados deste estudo se o período de pique de performance não ocorre em idades mais precoces. Numa análise comparativa entre os gêneros, embora a tendência de índices mais elevados de performance em todo o período analisado em prol dos rapazes, encontramos diferenças estatisticamente significativas (tabela 8) apenas nas idades de 9,11 , 12,13 e 14 anos.

$\mathrm{Na}$ análise das comparações entre as idades (quadro 10), chama a atenção a maior heterogeneidade dos resultados quando se comparam os dois gêneros sexuais. Para os rapazes, embora as diferenças não ultrapassam o índice de 3,05 segundos entre o escore mais baixo e o mais alto, as diferenças estatisticamente significativas ocorrem com maior freqüência.

\section{Gráfico 14}

Perfil de alguns estudos sobre salto em extensão

Feminino 7 a 15 anos

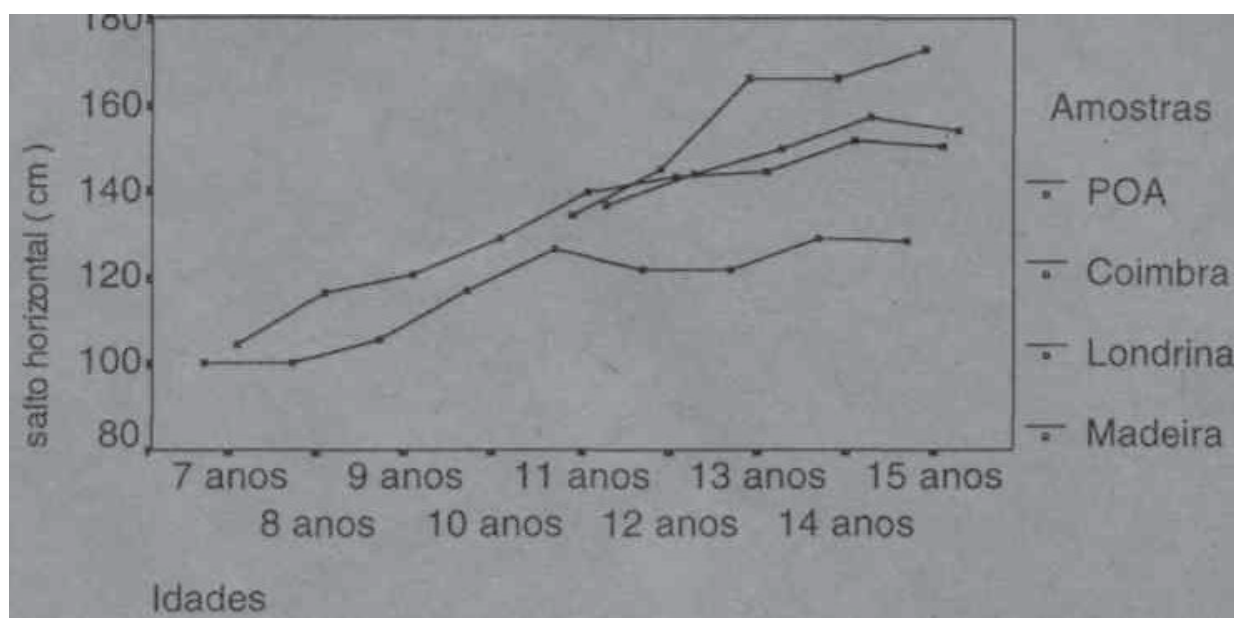

Gráfico 15

Teste de agilidade em relação ao sexo por idades

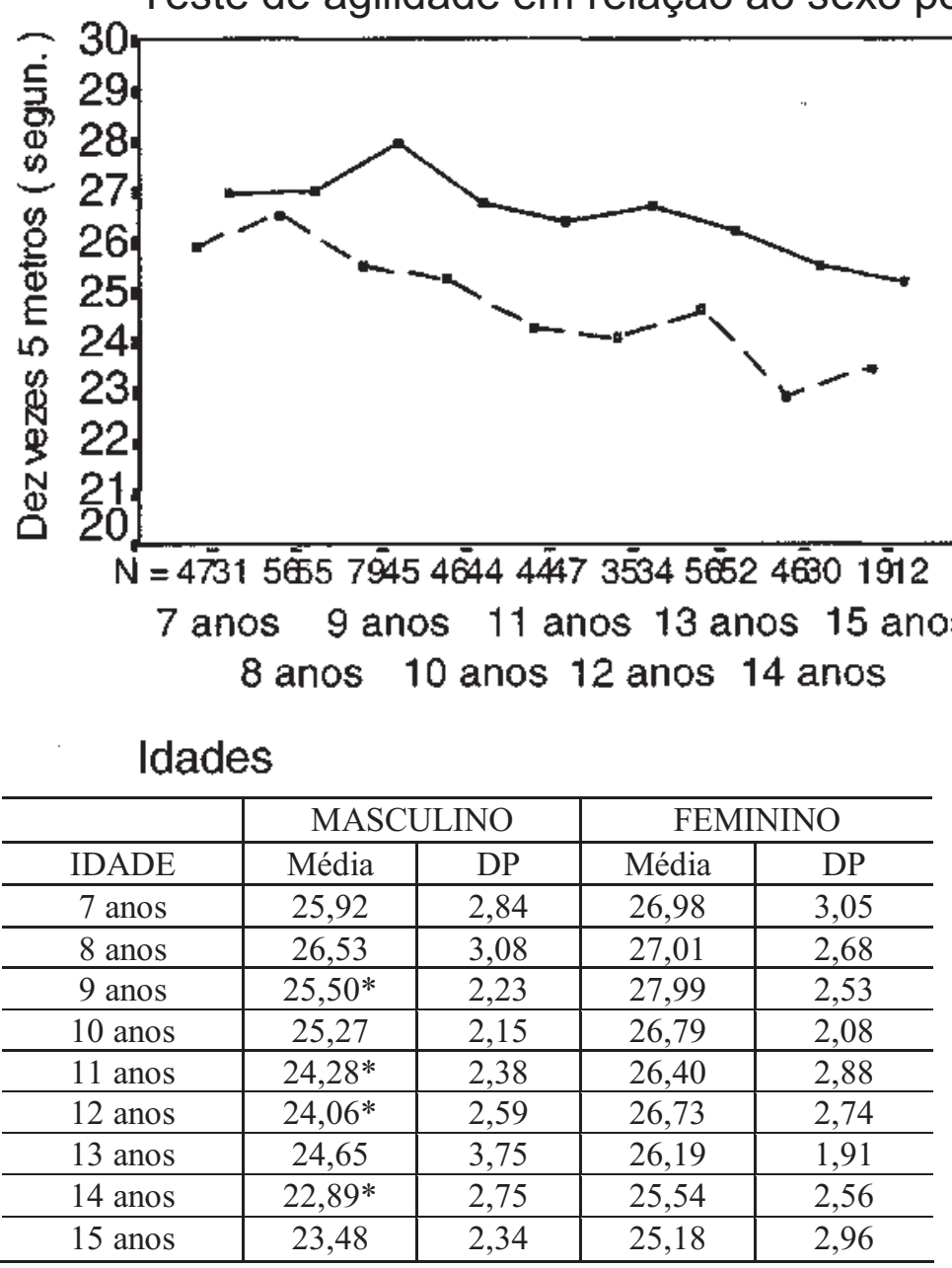

(*) Indicativo de diferença estatisticamente significativa para $p<0,05$.
SEXO

Masculino Feminino

Tabela7. Médias e desvios padrão referente ao teste de agilidade por sexo e idade. 
Gráfico 16

Perfil de alguns estudos sobre a agilidade

Masculino 7 a 15 anos

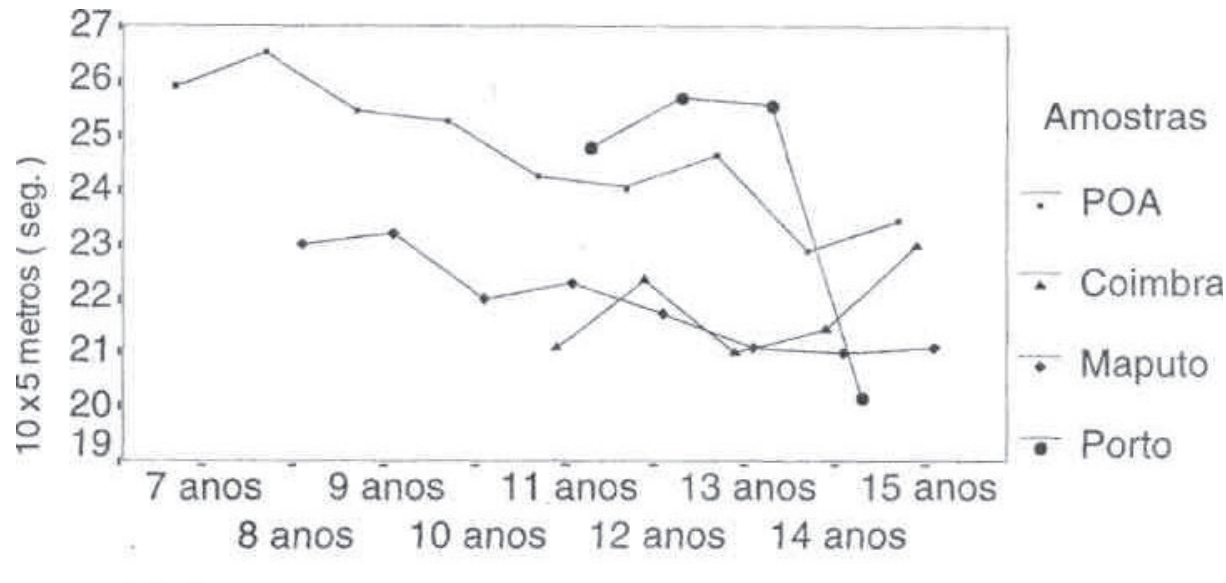

Idades

Gráfico 17

Perfil de alguns estudos sobre a agilidade

Feminino 7 a 15 anos

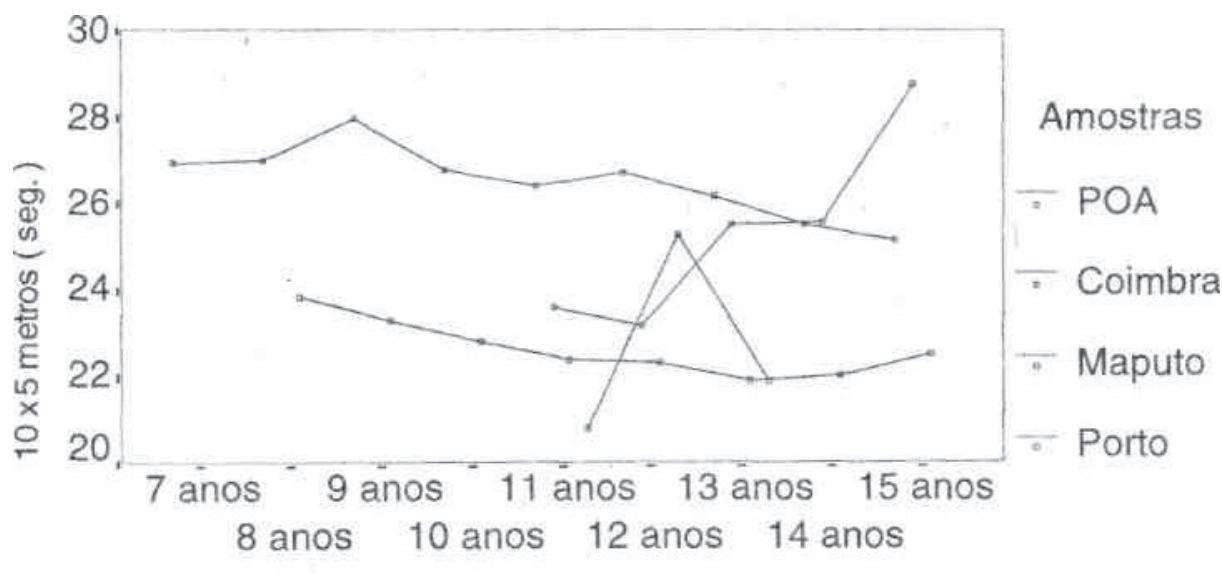

Idades

Quadro Matriz de comparações múltiplas (Duncan teste ) par o teste de agilidade

\begin{tabular}{|c|c|c|c|c|c|c|c|c|c|c|c|c|c|c|c|c|}
\hline \multicolumn{9}{|c|}{ Masculino } & \multicolumn{8}{|c|}{ Feminino } \\
\hline idade & $n$ & 8 & 9 & 10 & 11 & 12 & 13 & 14 & 7 & 8 & 9 & 10 & 11 & 12 & 13 & 14 \\
\hline 8 & $\mathrm{~ns}$ & & & & & & & & ns & & & & & & & \\
\hline 9. & ns & $*$ & & & & & & & ns & ns & & & & & & \\
\hline 10 & ns & $*$ & ns & & & & & & ns & ns & $*$ & & & & & \\
\hline 11 & $*$ & $*$ & $*$ & ns & & & & & ns & ns & $*$ & ns & & & & \\
\hline 12 & $*$ & $*$ & $*$ & ns & ns & & & & ns & ns & ns & ns & ns & & & \\
\hline 13 & $*$ & $*$ & $\mathrm{~ns}$ & ns & ns & ns & & & ns & ns & $*$ & ns & ns & ns & & \\
\hline 14 & $*$ & $*$ & * & * & $*$ & ns & $*$ & & $\mathrm{~ns}$ & $*$ & $*$ & $\mathrm{~ns}$ & ns & ns & ns & \\
\hline 15 & $*$ & $*$ & $*$ & $*$ & ns & ns & ns & ns & ns & ns & $*$ & ns & ns & ns & ns & ns \\
\hline
\end{tabular}

${ }^{*}$ ) Indicativo de diferença estatisticamente significativa para $p<0,05$.

(ns) Indicativo para diferença não significativa
Para as moças, os resultados mais homogênios representaram índices que, na maioria dos casos, não foram estatisticamente significativos. As diferenças foram exceção e situam-se curiosamente de forma clara em relação aos 9 anos que, quando comparados com os 10, 11, $14 \mathrm{e}$ 15 anos, apresentam índices de desempenho mais baixos. Todavia, nesse caso, as diferenças entre o maior e o menor resultado situa-se em 2,81 segundos.

Para fins de orientação para o planejamento das aulas de educação física, considerando que a maior diferença entre os resultados não ultrapassa 5,10 seg (9 anos feminino e 14 anos masculino), não parece ser necessário sugerir recomendações especiais quanto à constituição de turmas mistas e heterogêneas em relação às idades.

Observando o gráfico 16 , vamos verificar que, considerando a agilidade medida através do teste dos $10 \times 5$ metros, os rapazes de nossa amostra aos 12, 13 e 14 anos tendem a ter desempenho superior aos rapazes da cidade do Porto. Todavia, ao. longo do período etário observado, os resultados dos rapazes de Porto Alegre são significativamente inferiores aos rapazes de Coimbra e Maputo.

O gráfico 17 retrata $o$ comportamento das curvas de desempenho em agilidade para as moças em diferentes amostras. Verificamos que as moças de Porto Alegre estão com resultados inferiores às moças de Coimbra, Maputo e Porto. Todavia, aos 14 anos as porto-alegrenses se aproximam das portuguesas do Porto e superam-nas na idade de 15 anos. 
Quanto ao desempenho da velocidade de deslocamento $^{26}$ analisado a partir do corte transversal entre 7 a 15 anos, o gráfico 18 sugere um desempenho proporcionalmente equilibrado, tanto para os rapazes quanto para as moças. Todavia, deve ser realçada a presença de uma ligeira inflexão na curva aos 12 anos para as moças e aos 14 para os rapazes, possivelmente conseqüência dos efeitos morfo-funcionais inerentes aos processos maturacionais pubertários. Por outro lado, não se detecta com clareza, pela curva de desempenho das moças, um período de pique de performance para a velocidade de deslocamento. Talvez se possa inferir, pela tendência da curva, que esse período ocorra anteriormente aos 8 anos. Já para os rapazes, o período entre 7 e 8 anos sugere um pique de performance, mas, como referimos em relação às moças, não podemos, pela ausência de dados anteriores aos 7 anos, afirmar que não ocorra mais acentuadamente em idades inferiores.

Por outro lado, as comparações entre os gêneros sugerem diferenças estatisticamente significativas ao longo de quase todo o período de desenvolvimento (com exceção dos 13 e 15 anos). Esse dado, obviamente, sugere que em aulas de educação física que envolvam atividades de velocidade de deslocamento devem considerar as distintas competências entre rapazes e moças, embora, como veremos adiante, essas diferenças não ultrapassem o índice de 1,16 seg.

As comparações entre as idades apresentadas no quadro 8 nos mostram, para ambos os sexos, a ocorrência de freqüentes diferenças estatisticamente significativas. Tanto para os rapazes como para as moças predominam as diferenças entre as idades, todavia essas diferenças não ultrapassam a 1,07 seg. entre os rapazes e $0,84 \mathrm{seg}$. entre

as moças, sendo que, entre os índices extremos, a diferença fica em 1,16 seg., o que, convenhamos, não pareça constituir-se em obstáculo para atividades em conjunto.

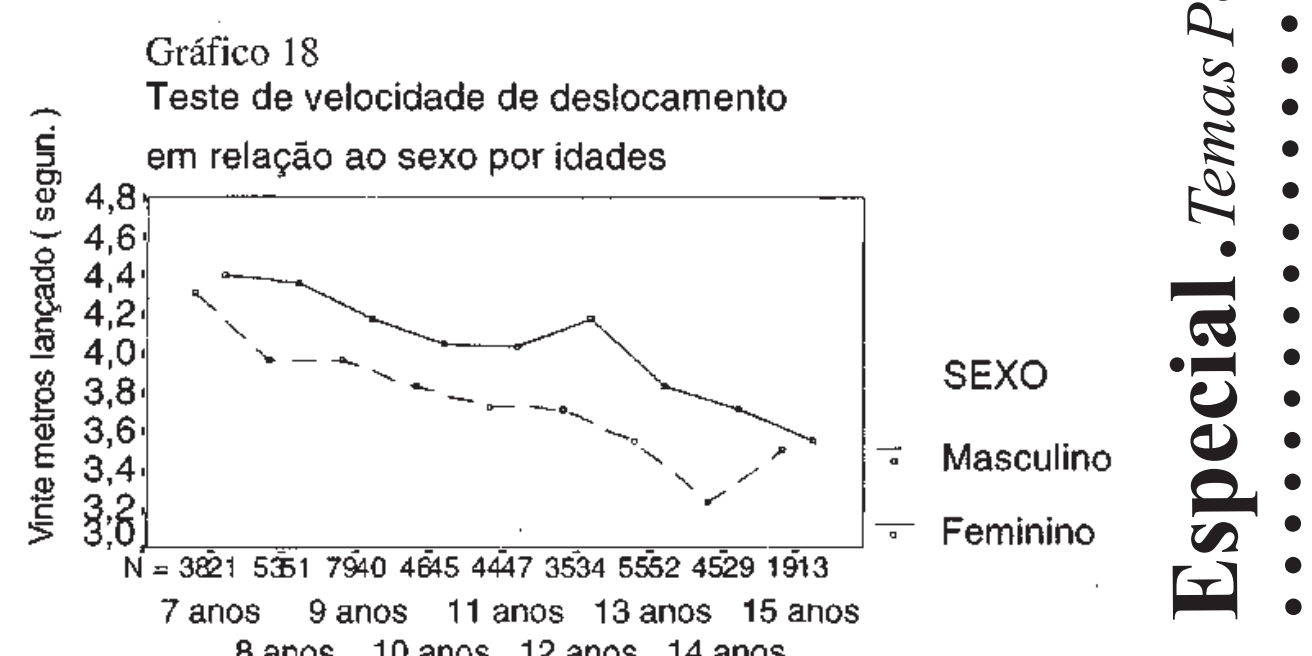

Idades

Tabela 8. Médias e desvios padrão referente ao teste de vinte metros por sexo e idade.

\begin{tabular}{c|c|c|c|c}
\hline & \multicolumn{2}{|c|}{ MASCULINO } & \multicolumn{2}{c}{ FEMININO } \\
\hline IDADE & Média & DP & Média & DP \\
\hline 7 anos & 4,30 & 0,33 & 4,39 & 0,31 \\
\hline 8 anos & $3,96^{*}$ & 0,10 & 4,35 & 0,07 \\
\hline 9 anos & $3,96^{*}$ & 0,30 & 4,17 & 0,37 \\
\hline 10 anos & $3,82^{*}$ & 0,22 & 4,04 & 0,35 \\
\hline 11 anos & $3,73^{*}$ & 0,31 & 4,02 & 0,38 \\
\hline 12 anos & $3,71^{*}$ & 0,37 & 4,16 & 0,43 \\
\hline 13 anos & $3,55^{*}$ & 0,35 & 3,83 & 0,30 \\
\hline 14 anos & $3,23^{*}$ & 0,24 & 3,71 & 0,17 \\
\hline 15 anos & 3,50 & 0,52 & 3,55 & 0,17 \\
\hline
\end{tabular}

(*) Indicativo de diferença estatisticamente significativa para $\mathrm{p}<0,05$.

Quadro Matri de comparações múltiplas (Duncan teste) para o teste vinte metros

\begin{tabular}{|c|c|c|c|c|c|c|c|c|c|c|c|c|c|c|c|c|}
\hline \multicolumn{9}{|c|}{ Masculino } & \multicolumn{8}{|c|}{ Feminino } \\
\hline idade & $n$ & 8 & 9 & 10 & 11 & 12 & 13 & 14 & 7 & 8 & 9 & 10 & 11 & 12 & 13 & 14 \\
\hline 8 & * & & & & & & & & ns & & & & & & & \\
\hline 9 & * & $\mathrm{ns}$ & & & & & & & $*$ & * & & & & & & \\
\hline 10 & * & * & * & & & & & & * & * & ns & & & & & \\
\hline 11 & * & * & * & ns & & & & & * & * & $*$ & ns & & & & \\
\hline 12 & $*$ & * & * & ns & ns & & & & * & * & ns & ns & ns & & & \\
\hline 13 & * & * & * & $*$ & $*$ & * & & & * & * & $*$ & \# & $*$ & $*$ & & \\
\hline 14 & * & * & * & $*$ & * & * & * & & * & * & * & & r & $-\mathrm{F}$ & $X W$. & \\
\hline 15 & * & $*$ & * & $*$ & * & * & ns & * & * & * & * & * & * & \# & * & ns \\
\hline
\end{tabular}

(*) Indicativo de diferença estatisticamente significativa para $\mathrm{p}<0,05$. 
Para a última variável analisada neste estudo, a resistência de longa duração ${ }^{27}$, medida através do teste de 9 minutos, os resultados demonstrados no gráfico 19 e tabela 9 sugerem as seguintes interpretações: ini- cialmente, tal como ocorreu com a força explosiva de membros inferiores, é evidente uma performance claramente superior dos rapazes em relação às moças durante a maior parte do período etário analisado (com diferenças estatisticamente sig-

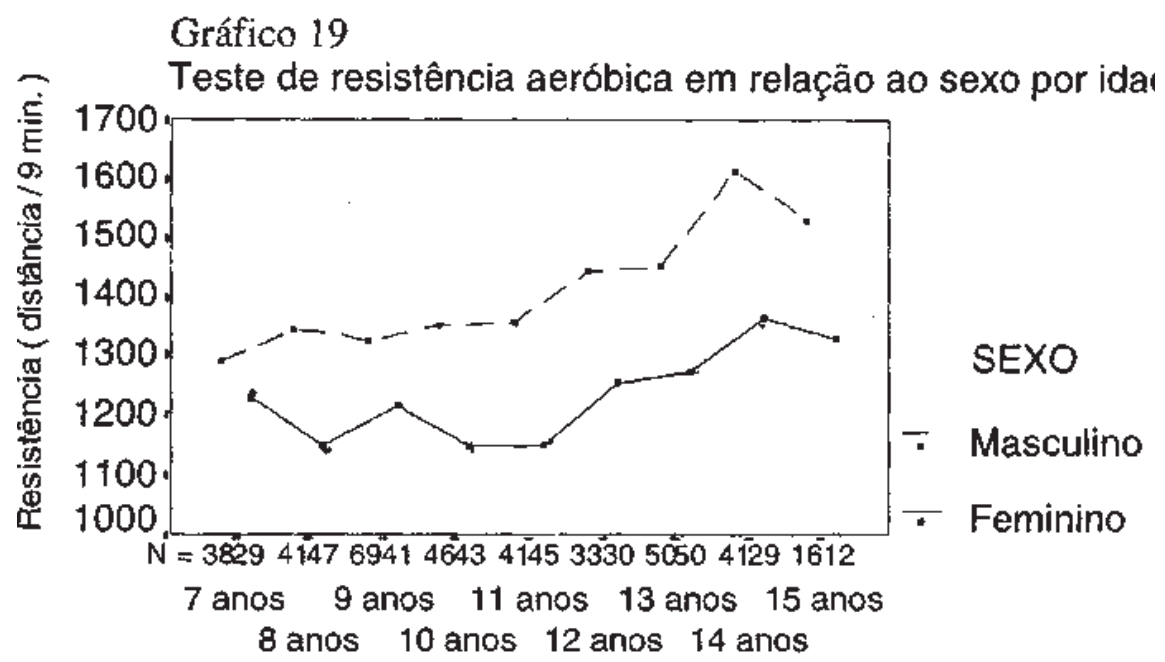

Idades

Tabela 9. Médias e desvios padrão referente ao teste de resistência por sexo e idade.

$\left.\begin{array}{c|c|c|c|c}\hline & \multicolumn{2}{|c|}{\text { MASCULINO }} & \multicolumn{2}{c}{\text { FEMININO }} \\ \hline \text { IDADE } & \text { Média } & \text { DP } & \text { Média } & \text { DP } \\ \hline 7 \text { anos } & 1289^{*} & 210,75 & 1231 & 157,22 \\ \hline 8 \text { anos } & 1345^{*} & 155,55 & 1152 & 132,15 \\ \hline 9 \text { anos } & 1326^{*} & 175,19 & 1218 & 133,86 \\ \hline 10 \text { anos } & 1352^{*} & 193,45 & 1153 & 151,33 \\ \hline 11 \text { anos } & 1358^{*} & 204,25 & 1150 & 182,98 \\ \hline 12 \text { anos } & 1442^{*} & 221,18 & 1254 & 158,95 \\ \hline 13 \text { anos } & 1451 & 176,31 & 1271 & 182,41 \\ \hline 14 \text { anos } & 1614^{*} & 128,73 & 1367 & 32,00 \\ \hline 15 \text { anos } & 1530 & 196,04 & 1331 & 265,83\end{array}\right)<0,05$.

Quadro 10. Matriz de comparações múltiplas (Duncan teste ) para o teste de resistência de longa duração

\begin{tabular}{|ccccccccc|cccccccc|}
\hline \multicolumn{10}{c|}{ Masculino } & \multicolumn{1}{c|}{ Feminino } \\
idades & 7 & 8 & 9 & 10 & 11 & 12 & 13 & 14 & 7 & 8 & 9 & 10 & 11 & 12 & 13 & 14 \\
8 & $\mathrm{~ns}$ & & & & & & & & ns & & & & & & & \\
9 & $\mathrm{~ns}$ & $\mathrm{~ns}$ & & & & & & & $\mathrm{~ns}$ & $\mathrm{~ns}$ & & & & & & \\
10 & $\mathrm{~ns}$ & $\mathrm{~ns}$ & $\mathrm{~ns}$ & & & & & & $*$ & $\mathrm{~ns}$ & $\mathrm{~ns}$ & & & & & \\
11 & $\mathrm{~ns}$ & $\mathrm{~ns}$ & $\mathrm{~ns}$ & $\mathrm{~ns}$ & & & & & $\mathrm{~ns}$ & $\mathrm{~ns}$ & $\mathrm{~ns}$ & $\mathrm{~ns}$ & & & & \\
12 & $*$ & $*$ & $*$ & $*$ & $\mathrm{~ns}$ & & & & $\mathrm{~ns}$ & $*$ & $\mathrm{~ns}$ & $*$ & $*$ & & & \\
13 & $*$ & $*$ & $*$ & $*$ & $*$ & $\mathrm{~ns}$ & & & $\mathrm{~ns}$ & $*$ & $\mathrm{~ns}$ & $*$ & $*$ & $\mathrm{~ns}$ & & \\
14 & $*$ & $*$ & $*$ & $*$ & $*$ & $*$ & $*$ & & $*$ & $*$ & $*$ & $*$ & $*$ & $*$ & $*$ & \\
15 & $*$ & $*$ & $*$ & $*$ & $*$ & $\mathrm{~ns}$ & $\mathrm{~ns}$ & $\mathrm{~ns}$ & $\mathrm{~ns}$ & $*$ & $*$ & $*$ & $*$ & $\mathrm{~ns}$ & $\mathrm{~ns}$ & $\mathrm{~ns}$ \\
\hline
\end{tabular}

(*) Indicativo de diferença estatisticamente significativa para $\mathrm{p}<0,05$.

(ns) Indicativo de diferença estatisticamente não significativa nificativas aos $7,8,9,10,11$, 12,13 e 14 anos). Esses resultados, evidentemente, impõe a necessidade de considerarmos as diferenças entre os gêneros na estruturação e planejamento das aulas de educação física e programas de treino voltados à capacidade aeróbica.

Os resultados, da mesma forma, sugerem um desenvolvimento progressivamente equilibrado na performance dos meninos até os 13 anos, quando ocorre um pique de desempenho até os 14 anos com sucessiva inflexão da curva dos 14 aos 15 anos. Provavelmente, o período próximo aos 13 anos se configura num período sensível para o desenvolvimento da resistência de longa duração para os meninos. Quanto as meninas, os dados no período entre os 7 e 10 anos não permitem conclusões seguras, todavia parece ocorrer um pique de performance entre os 11 e 12 anos. Portanto, confirmada essa hipótese, pode-se inferir que o pique de performance das meninas antecede proximamente em um ano aos dos meninos, fato coerente com o dimorfismo sexual conseqüente da maturação biológica.

A matriz de comparações múltiplas entre as idades para a resistência de longa duração (quadro 10) apresenta um quadro relativamente homogêneo. Para o sexo masculino, fica claramente evidenciado a composição de dois grupos etários: o primeiro entre os 7 e 10 anos e o segundo entre 11 a 15 anos. Em relação às moças, o comportamento é mais heterogêneo que o dos rapazes. Chama a atenção os resultados dos 7 anos que são significativamente inferiores apenas aos 
resultados dos 15 e dos 9 anos que são inferiores aos dos 14 e 15 anos. Considera-se, ainda, o fato de que, no período entre 10 e 11 anos, provavelmente por conseqüência do aumento significativo no peso e estatura, a tendência da performance na prova de resistência é inferior às demais idades.

Por suposto, a partir dos dados apresentados, considera-se relevante considerarmos alguns cuidados em relação à determinação de cargas de trabalho aeróbico. Desse modo, tal como aconteceu com as diferenças detectadas entre os gêneros sexuais, as diferenças entre as faixas etárias não podem ser desprezadas.

Em relação aos índices de saúde propostos por Cooper para a resistência aeróbica, tendo como parâmetro a velocidade média da corri$\mathrm{da}^{28}$, nossos rapazes estão com resultados inferiores aos 14 e 15 anos e as moças, a partir dos 10 anos. Esses dados, mais uma vez, sugerem a necessidade dos programas de educação física tomarem para si preocupações com a aptidão física referenciada à saúde. Todos sabemos que a resistência aeróbica é um importante indicador da capacidade cardiovascular, e mais: sabemos que as doenças relacionadas ao sistema cardiovascular representam a maior causa de mortes nos países industrializados, constituindo-se num dos mais importantes problemas de saúde pública.

\section{Em forma de conclusão}

Em forma de conclusão à primeira parte deste ensaio, vamos pontuar alguns resultados da investigação que en- tendemos se constituírem em argumentos empíricos capazes de subsidiar os indicadores ou teses que propomos debater na secção seguinte. Desse modo, vamos considerar os seguintes principais resultados:

(a) Os dados referentes ao peso corporal e estatura que indicam os estágios de crescimento dessa população sugerem, principalmente no período compreendido entre os 10 e 12 anos e, posteriormente, aos 14 anos, a evidente presença de dimorfismos de gênero. Ocorrem diferenças significativas entre rapazes e moças, tanto em peso como em estatura, entre os 10 e 12 anos em prol das moças e aos 14 anos em prol dos rapazes;

(b) Considerando a estratificação por idade, podemos verificar que, para ambos os sexos (embora seja mais evidente para os rapazes), a idade cronológica se configura numa variável interveniente de muito significado. Ao observarmos os quadros 2 e 3, podemos visualizar que, ao transitarem de uma idade para a(s) seguinte(s), normalmente os índices de peso e estatura se diferenciam de forma estatisticamente significativa ${ }^{29}$ com as médias mais elevadas em prol dos sujeitos mais velhos;

(c) Considerando as variáveis de aptidão física, as diferen ças entre gêneros se compor tam da seguinte forma: varia ções pontuais ocorrem no tes te de flexibilidade, onde as diferenças são significativas apenas nas idades de 10 e 13 anos em prol das moças; no teste de força de preensão manual, após os 14 anos, os rapazes superam as moças e no teste de resistência-força abdominal, os rapazes são superiores entre os 11 e 14 anos. Nos demais testes (força explosiva de membros inferiores, agilidade, velocidade de deslocamento, resistência aeróbica), ocorrem, na maior parte dos períodos analisados, índices significativamente mais elevados em prol dos rapazes;

(d) Considerando a estratificação por idade nas provas de aptidão física, verificamos que, para a maioria dos testes (flexibilidade, resistência-força abdominal, força explosiva de membros inferiores, resistência), a idade, pelo menos nos intervalos próximos a 2 anos, não se constitui em variável interveniente de significado. Ao confirmarem-se esses dados, podemos sugerir que a variável atributiva gênero sexual impõe mais diferenças entre os grupos que a variável idade cronológica;

(e) Nossos rapazes e moças apresentam índices relativamente baixos comparativamente a outras populações de crianças e jovens de mesma faixa etária nos seguintes testes: mobilidade da coluna vertebral, força explosiva de membros inferiores e agilidade;

(f) Nossos rapazes e moças apresentam índices equivalentes comparativamente a outras populações de mesma faixa etária nos testes de força de preensão manual e força-resistência abdominal.

(g) Considerando os índices que Cooper (1985) propõe como parâmetro de aptidão física para saúde, verificamos que nossos rapazes e moças estão, em alguns casos, sobre a linha limite e, em outros tantos, abaixo dessas normas ${ }^{30}$. 


\section{PARTE}

\section{Os temas polêmicos}

Os principais resultados da investigação como indicadores para o planejamento das aulas de educação física

A partir dos dados e inferências apresentadas ao longo do trabalho descritivo, alguns indicadores para o planejamento das aulas de educação física referenciadas à promoção da saúde podem ser identificados. É evidente que, para além daqueles aqui discutidos, muitos outros poderão surgir, e é nesse sentido que gostaríamos de estimular os leitores para que, com suas experiências científicas e pedagógicas diversificadas, possam participar ativamente do debate que temos a pretensão de provocar.

Vamos propor alguns tópicos e o faremos de forma suscinta de modo a não tornar o trabalho por demais extenso. Por outro lado, os leitores devem considerar que nossas sugestões não são conclusivas e, portanto, devem ser consideradas no limite estrito de uma pauta com o intuito de balizar o debate.

Tema 1. A aptidão física relacionada à saúde (AF) como conteúdo das aulas de educação física (EF)

Num artigo que trata de variáveis ligadas ao crescimento e ao desenvolvimento físico e motor e que pretende estimular o debate sobre a EF escolar, talvez a primeira questão seja: Será pertinente à EF preocupações com o desenvolvimento da aptidão física?

Em nosso ponto de vista, como afirmamos na introdução, acreditamos que sim. Todavia, essa posição muitas vezes é colocada em cheque no âmbito de nossa comunidade científica e pedagógica. Não obstante, acreditamos que a resistência que se possa ter em relação a AF decorre de uma concepção enviesada de seu conceito. Se não vejamos: primeiramente, parte dessas críticas concebem à $\mathrm{AF}$ como um construto ligado ao rendimento desportivo ou à ergonomia. Nessa perspectiva, consideramno como um conteúdo que encerra pressupostos de exclusão ou de seleção, seja para o desporto ou para o trabalho. Ora, posições nessa linha de raciocínio desconsideram o perfil multidimensional da AF. Desconsideram que AF é um construto que não pode ser definido a não ser de forma operacional, ou, em outras palavras, aptidão física sempre requer uma questão complementar: AF para quê? ${ }^{31}$ Certamente, poderá ser AF para o rendimento desportivo, poderá, da mesma forma, ser AF para o trabalho, no entanto o que defendemos para a EF será uma definição de AF referenciada a saúde $^{32}$, ou seja, AF objetivando alterações no estilo de vida com o intuito de prevenir a ocorrência de doenças hipocinéticas ou de outras origens que, como sabemos, muitas delas têm suas raízes na infância.

Nessa visão, diversos autores, adotando metodologias científicas rigo$\operatorname{rosas}^{33}$, dedicaram-se a operacionalizar o conceito de AF relacionada à saúde, considerando como va- riáveis marcadoras a aptidão cardiorrespiratória, resistência muscular, força muscular, composição corporal e flexibilidade. Essas variáveis marcadoras são identificadas através de testes de medida e são normatizadas a partir de estudos epidemiológicos, configurando índices de AF considerados adequados ao nível de saúde pública ${ }^{34}$.

Analisando os resultados de nossa população, verificamos, por exemplo, que nossas moças apresentam índices inferiores ao limite proposto por Cooper $(17 \mathrm{~cm}$ para o seat and reach), aos 8 e aos 12 anos, estando sobre o limite nas idades de 7, 9, 10 e 11 . Para os rapazes, os índices estão abaixo aos 9, 10, 11, 13 e 14 anos, sobre o limite aos 8 , 12 e aos 15 anos. Por outro lado, quando comparamos nossa amostra com outras populações (gráficos 7 e 8), verificamos que, tanto para os rapazes como para as moças, obtemos índices mais baixos daqueles propostos por Cooper. Para a força-resistência abdominal, o quadro se repete: nossas moças estão abaixo entre 9 a 15 anos, enquanto os meninos estão abaixo a partir dos 12 anos. Para resistência aeróbica, considerando a velocidade média ${ }^{35}$ da corrida, somente aos 14 e 15 anos nossos rapazes estão abaixo dos índices de Cooper, enquanto que as moças, a partir dos 10 anos, apresentam índices mais baixos daqueles propostos por esse pesquisador.

\section{Como podemos obser-} var, nossos estudantes obtiveram resultados preocupantes em relação a AF referenciada à saúde e, portanto, cabe retornar à questão inicial: Não será pertinente à EF preocu- 
pações com o desenvolvimento da aptidão fisica relacionada ásaúde?

Partindo-se do pressuposto de que a escola enquanto instituição social deve ter como princípio colaborar para o desenvolvimento global dos educandos e que a promoção da saúde consubstancia-se, sobretudo, como uma questão pedagógica, parece-nos que se faz necessário o desenvolvimento de estratégias pedagógicas que dêem conta, também, do desenvolvimento da $\mathrm{AF}$ relacionada à saúde. $\mathrm{E}$, nessa perspectiva, qual o componente curricular que tem, entre outros objetivos, o de fornecer oportunidades aos alunos de tornarem-se ativos fisicamente durante e após o seu processo de escolarização? Certamente não é esse o papel da matemática, da língua portuguesa, das artes plásticas, enfim, das demais disciplinas que compõem o currículo de nossas escolas. É claro que as ações pedagógicas voltadas à promoção da saúde devem se dar de forma integrada entre todas as disciplinas, porém cada componente curricular tem a sua especificidade - especificidade essa que the fornece a legitimidade de se constituir enquanto elemento integrante do currículo escolar.

Do nosso ponto de vista, entendemos que o desafio que se coloca à EF é, entre outros, promover a realização de estratégias conducentes ao estabelecimento de um estado geral de saúde em crianças e jovens. Desse modo, o aumento das atividades físico-desportivas e o fomento aos hábitos de exercícios regulares, como forma de promoção da saúde pública, impõe à EF um papel de relevância na realização desses objetivos. Portanto, acreditamos que se faz necessária a inclusão, nas aulas da referida disciplina escolar, atividades referenciadas ao desenvolvimento de algumas principais capacidades motoras e condicionais.

Evidenciamos carências em nossas crianças e jovens, por exemplo, no âmbito da resistência e força abdominal, na resistência aeróbica, na flexibilidade, e, por considerar tais variáveis como indicadores relevantes aos padrões de aptidão física referenciada à saúde, entendemos que devem ser devidamente desenvolvidas nas aulas de educação física escolar.

Quanto a flexibilidade, cremos que o principal propósito é o de manter os músculos com determinado grau de elasticidade de forma que em sua atividade normal se evitem encurtamentos. É evidente que para atingir esses parâmetros se torna necessário exercitálos regularmente. Todos sabemos que as pessoas necessitam um nível razoável de flexibilidade para evitar problemas posturais e conseqüente dores, por exemplo, na zona lombar; além do mais devemos ter em conta que flexibilidade deficiente aumenta os riscos de lesões ao realizarmos atividades físicas e desportivas.

Consideramos adequado que nas aulas de educação física, normalmente em sua parte inicial, possamos desenvolver exercícios de flexibilidade através de alongamentos realizados de forma lenta, seguindo toda a amplitude das articulações, mantendo a postura por alguns segundos.
Sobre a resistência e força muscular, desde o ponto de vista da promoção da saúde, cremos que seja importante desenvolver e manter índices de desempenho capazes de permitir a manutenção de uma atitude postural adequada. Nessas condições, é muito importante que o professor exija distintos níveis de intensidade em diversos exercícios, de modo que os alunos possam eleger aqueles que melhor se adaptem a suas possibilidades e necessidades. Exercícios de resistência muscular localizada, exercícios de força relativa (força relacionada ao próprio peso corporal), exercícios de saltos que podem ser realizados em forma de jogos e contestes devem constituir os programas de atividade das aulas de educação física.

As atividades aeróbicas, sem dúvida, são conteúdos relevantes à promoção da saúde. Caracterizando-se como atividades moderadas e contínuas, consubstanciam-se em requisitos para a realização das atividades físicas cotidianas. Configurando-se em atividades que envolvem grandes grupos musculares e, como tal, exigindo a ativação do sistema cardiovascular e respiratório, seu treino exige um adequado planejamento. Todavia, não devemos entender que as aulas devam constituir-se em exercícios monótonos e repetitivos (corridas de longa duração, por exemplo) que não resultam alentadoras para a maioria dos alunos. Desse modo, como afirmam Valeret et Devís (1992), se pretendemos que a participação ativa, num enfoque de promoção da saúde, seja uma experiência agradável e positiva que motive a repeti-la, deveremos evitar que se convertam 
em sacrifícios penosos. Portanto, as atividades que desenvolveremos deverão ser variadas, com possibilidade de serem realizadas por grupos e, preferencialmente, em forma de jogo.

Em síntese, queremos reforçar a tese que defendemos neste estudo. Independente da criatividade e das formas diversas que poderão ser utilizadas para o desenvolvimento das atividades referentes a AF relacionada à promoção da saúde, entendemos que esses conteúdos devam constituir-se num dos principais objetivos da EF escolar.

Tema 2. Fundamentos do exercício físico relacionado à saúde: teoria e prática

Como refere Almond $(1992)^{36}$, o papel que joga o exercício físico na promoção da saúde e bem-estar está bem assentado em evidências científicas que demonstram claramente as vantagens de exercícios adequados, que se realizam freqüentemente e se mantêm durante toda a vida sobre: o desenvolvimento e crescimento somato-motor; o adequado funcionamento dos sistemas cardiovascular e músculo-esquelético; a redução dos riscos de determinadas enfermidades, assim como em grupos especiais, fomentando uma autonomia crescente e uma diminuição de incapacidades relacionadas com a inatividade física; a melhoria do controle e gestão das deficiências existentes (por exemplo, asma e diabete) e a contribuição ao bem-estar mental e psicológico, a um melhor estado de humor e a uma consideração positiva da imagem corporal.
Nessa perspectiva, estamos convictos que é inerente aos programas de EF estimular padrões de atividades freqüentes com objetivos a longo prazo de ajudar a que nossos alunos reconheçam os exercícios físicos, os desportos e a AF como fatores coadjuvantes nos programas de promoção da saúde.

Portanto, entendemos que os programas de EF deverão proporcionar oportunidades para que crianças e jovens vejam favorecidos os processos de maturação mediante um crescimento e desenvolvimento equilibrado dos sistemas orgânicos; adquiram o conhecimento, as habilidades, as aptidões e a compreensão para reconhecer os valores do exercício físico para a saúde; aprendam como adotar um estilo de vida ativo e manter um compromisso com a vida ativa e, é muito importante salientar, instrumentalizem-se para uma prática desportiva autônoma.

Todavia, desenvolver tais pressupostos requer que os conteúdos da EF focalizem um conjunto de conhecimentos básicos que nossos alunos deverão aprender simultaneamente às ações práticas, tais como: os efeitos, a curto e a longo prazo, dos exercícios sobre o organismo; estratégias de manutenção de peso ideal; formas de relaxamento, recuperação e descanso adequados depois de práticas de atividades desportivas; exercícios físicos seguros e efetivos à promoção da saúde; riscos e benefícios dos exercícios referenciados à saúde; prescrição de exercícios, entre outros.

Não obstante, gostaríamos de sublinhar que tais con- teúdos teóricos devem incorporar nosso plano de ensino de forma simultânea às práticas desportivas, caso contrário corremos o risco de cair em incoerências do tipo ensinar conceitos e não proporcionar aos alunos a possibilidade de adquirir o conhecimento prático básico de como desenvolvê-los.

Tema 3. O princípio da individualidade. A organização das turmas para as aulas de educação física

Em relação às questões didático-pedagógicas que se configuram no pano de fundo deste estudo, os dados do estudo descritivo sugerem a necessidade de se considerar como relevante a discussão sobre a constituição de turmas mistas ou separadas entre gêneros sexuais, bem com a heterogeneidade entre faixas etárias nas aulas de EF e desportos. Temos a convicção de quanto é polêmico este tema, não obstante é importante ressaltar que muitas vezes essa discussão é realizada tendo como base a preferência dos professores em ministrar suas aulas para turmas mistas ou não, ou ainda, tomando-se por base critérios oriundos da experiência cotidiana, sem considerar critérios inerentes ao rigor da investigação científica.

Gostaríamos de suscitar a discussão sobre a constituição das turmas tendo como referencial um dos objetivos da EF escolar: propiciar ao aluno, no decorrer do seu processo de escolarização, oportunidades de construir um repertório motor o mais diversificado possível. Entendemos que a principal função social da escola é o trato com o conhecimento construído histo- 
ricamente e, nesse sentido, as práticas esportivas (os jogos, a dança, as modalidades esportivas, a ginástica, a capoeira, etc.) consubstanciam-se como elementos culturais a serem apropriados pelos estudantes, sempre na perspectiva de estabelecer uma tensão permanente entre o esporte na escola e o esporte da escola, conforme Vago (1997). Nessa perspectiva, portanto, faz-se necessária a análise das diferenças entre os sexos e faixas etárias com o intuito de verificarmos se essas podem vir a comprometer a realização desse objetivo da EF na escola e que alternativas podemos levantar para lidar com essa situação no cotidiano escolar.

Em favor das turmas separadas por gênero não podemos deixar de sublinhar, por exemplo, que, no período de 10 a 12 anos, rapazes e moças se diferenciam de forma muito significativa em relação ao peso corporal e à estatura, e se percebermos que esses dados são indicadores de um plano mais adiantado de maturação biológica em prol das moças, não é de todo despropositado se pensar que motivações, interesses sociais, atitudes e valores estejam presentes como fatores diferenciais entre os gêneros nesse período. Entretanto, até que ponto tais argumentos nos permitem apostar em aulas mistas ou separadas por gênero sexual?

Por outro lado, ainda em defesa de turmas separadas por gênero, poderíamos argumentar que, se por um lado, as moças apresentam maiores índices de crescimento no período de 10 a 12 anos, por outro lado, devemos ter ente que as variáveis de $\mathrm{AF}$ como a velocidade de deslocamento, força explosiva de membros inferiores, agilidade e resistência aeróbica apresentam índices mais elevados para os rapazes em quase todos o períodos etários analisados pela investigação. Poderíamos, quem sabe, argumentar no sentido de que se as atividades oferecidas pelas aulas de EF nas séries iniciais/I Ciclo utilizam atividades em que essas propriedades são preferencialmente exigidas (contestes, estafetas, jogos pré-desportivos como o "caçador", jogo dos dez passes, jogos de pegar, etc), poderíamos concluir que grande parte das meninas estão em desvantagem.

Por outro lado, em prol da constituição de turmas mistas, poderíamos referir, em certa medida, que as diferenças extrapolam as questões de gênero uma vez que:

(1) Há uma porcentagem de meninos (em torno de 30\%) que, devido a questões de constituição corporal, maturação ou por apresentarem um desempenho abaixo da média de sua turma, também se encontram em desvantagem.

(2) Há meninas (também em torno de $30 \%$ ) que apresentam desempenho semelhante à média dos meninos e, dessa forma, não têm dificuldades de participar de atividades que envolvam as variáveis supracitadas.

Ainda em defesa da constituição de turmas mistas para a prática da EF, poderíamos argumentar que tal situação não impede que, em determinados momentos, sejam formados grupos de trabalho a partir dos níveis de prestação desportiva.

\section{Como podemos obser-}

var, existem argumentos capazes de justificar as duas possibilidades no que se refere à constituição das turmas para as aulas de EF.

Todavia, ainda há uma terceira possibilidade a ser considerarada, a organização de turmas independentemente do gênero sexual, tomando como referência os níveis de prestação desportiva e as diferentes faixas etárias. Conforme demonstramos anteriormente neste artigo, os resultados obtidos indicam a possibilidade de delimitar três períodos, mais ou menos homogênios, onde poderíamos atuar no âmbito da AF referenciada à saúde, com conteúdos e estratégias comuns. Esses períodos correspondem, mais ou menos, dentro de certo grau de liberdade: Fase 1- entre 7 a 9 anos; Fase 2- entre 10 a 12 anos e Fase 3- entre 13 a 15 anos. No entanto, para viabilizar essa alternativa, as aulas de EF seriam realizadas no turno oposto ao das demais disciplinas, na medida em que as turmas de EF poderiam não coincidir com as turmas das demais disciplinas curriculares. Da mesma forma, para a constituição de turmas pelo critério da prestação desportivo-motora, seria necessário avaliações que evidenciassem indicadores capazes de formar grupos mais ou menos homogêneos.

É evidente que uma proposta desse feitio exigiria alterações significativas no cotidiano escolar, da mesma forma, provavelmente, um grande número de argumentos de diversas matizes teóricas poderiam obstaculizar a experiência, mesmo antes de ser testada. Mas, independente 
das reações que possa gerar um proposta dessa ordem (ou as demais que explicitamos ao longo desse ensaio), temos a certeza de que se trata de um tema polêmico que esperamos seja capaz de estimular o debate, que, enfim, é a proposta das páginas centrais da Revista Movimento.

\section{REFERENCIAS \\ BIBLIOGRÁFICAS}

ALMOND, L. El ejercicio físico y salud en la escuela. In: DEVIS, J.J ; VELERT, C.P. Nuevas perspectivas curriculares en educación fisica. Barcelona: INDE, 1992, p. 47-55.

AMERICAN ALLIANCE FOR HEALTH.PHYSICAL EDUCATION AND RECREATION. Youth Fitness Test Manual. Washington, DC, 1976.

_. Youth Fitness Test Manual. Wa shington, DC, 1980.

_. Youth Fitness Test Manual. Wa shington, DC, 1988.

ANJOS, L. A. ; BOILEAU, R. Avaliação de componentes da aptidão física de escolares de baixa renda da baixada fluminense, Estado do Rio de Janeiro. Revista Brasileira de Ciências do Esporte v.9, n.2, p.62-67, 1988.

BENTO, J. O. Desporto, saúde, vida. Em defesa do desporto. Lisboa: Livros Horizonte, 1991.

_. Para uma formação desportivacorporal na escola. Lisboa : Livros Horizonte, 1989.

CARPERSEN, C. J. et al. Physical activity, exercise and physical fitness: definitions and distinctions for health-related research. Public Health Reports. v.100, p.126-130, 1985.

CONSELHO DA EUROPA. Eurofit. Manual para os testes de aptidão Física. Lisboa : Ministério de Educação, 1990.

COOPER, K. Saúde e boa forma para seu filho. Rio de Janeiro: Nórdica, 1991, p. 113-114.
CUNHA, D. S. Estudo sobre a influência do nível sócio-econômico na aptidão motora. Santa Maria: UFSM, 1985. (dissertação de mestrado).

CURETON, K. J. Commentary on children and fitness: A public health perspective. Research Quartelyfor exercise and sport. v.58, n.4, p.315-320, 1987.

DEVIDE, F. P. Educação Física e saúde: em busca de uma reorientação para a sua práxis. $R e-$ vista Movimento. Porto Alegre, v.3, n.5, p.44-55, 1966.

DEVÍS, J. ; VELERT, C. P. Nuevas perspectivas curriculares en educación fisica: Ia salud y los juegos modoficados. Barcelona: Inde, 1992.

DUARTE, F. et al. Aptidão fisica da população escolar da região autônoma da Madeira. Madeira : Universidade da Madeira, 1997.

FARIA Jn, A. Educação fisica, desporto e promoção da saúde. Oeiras : Câmara Municipal de Oeiras, 1991.

FARINATTI, P. V. Educação física escolar e aptidão física. Um ensaio sob o prisma da promoção da saúde. Revista Brasileira de Ciencias do Esporte. Santa Maria, v.16, n.1, p.4248, 1994.

FERREIRA, M. et al. Comparação da aptidão física de escolares de Itaquera e São Caetano do Sul. Revista Brasileira de Ciência e Movimento. São Caetano do Sul, v.4, n.2, p. 19-27, 1990.

GAYA, A. ; Torres, L. A influência do nível sócio-econômico e do sexo no perfil dos hábitos de vida de crianças de 7 a 11 anos praticantes de desporto extraclasse. In: Simpósio de Ginástica e Desporto. Anais. Pelotas : UFPEL, 1996.

GAYA, A. Educação física. Educação e saúde? Revista de Educação Física da VEM. Maringá, n.1,p.36-38, 1989.

GUEDES, D. P. ; BARBANTI, V Desempenho motor em crianças e adolescentes. Revista Paulista de Educação Física. São Paulo, v.9, n.1, p.37-50, 1995.
GUEDES, D. P. ; GUEDES, J. Sugestão de conteúdo programático para programas de educação física escolar direcionados à promoção da saúde. APEF-Londri$n a$, v.9, n.16, p.3-14, 1994.

_ . Implementação de programas de educação física escolar direcionados à promoção da saúde. Revista Brasileira de Saúde Escolar, v.3, p. 1-4, 1994.

KALINOWSKY, F. G. Variáveis de aptidão fisica estudadas através da bateria de testes EUROFIT relacionadas aos niveis sócio-economicos em escolares das zonas urbana e rural do município de Ponta Grossa. São Paulo : Universidade de São Paulo, 1995 (dissertação de mestrado).

KUNTZLEMAN, C. T. ; REIFF, G.G. The decline in amerivan children's Leveis. Research Quartelyfor Exercise and Sport, v.63, p.107-111, 1992.

MALINA, R. Racial/Ethnic variation in the motor development. Paper prepared for de 25th aniversary os the AISEP. Lisboa, 1988

MARQUES, A. T. Desenvolvimento da capacidade de prestação de resistência. Estudo aplicado em crianças e jovens do $5^{\circ}$ ao $9^{\circ}$ ano de escolaridade da região do Grande Porto. Porto: ISEFUP, 1988. (tese de doutorado).

MATSUDO, V. Modelo biológico para diagnóstico de la salud y prescrición de actividad física. Archivos de Medicina dei Deporte. Barcelona, v. 10, n.37, p.35-45, 1993.

NEGRÃO, C. E. Condição sócioeconômica e desenvolvimento físico de crianças. São Paulo : USP, 1981 (dissertação de mestrado).

NUNN ALLY, J. Psychometric theory. 2.ed., New York : McGrawHill, 1978.

OSTYN, M. et al Somatic and motor developemnt of Belgian Secondary schoolboys. Norms and standards. I Katholieke. Leuve : Universiteit Leuven, 1980.

PEREIRA, M. J. M. S. Aptidão fisica e o desporto escolar. Porto : 
Universidade do Porto, 1996. (dissertação de mestrado).

PR1STA, A. Influência da actividade fisica e dos factores sócio-econômicos sobre as componentes da estrutura do valor fisico relacionados com a saúde. Estudo em crianças e jovens moçambicanos. Porto : FCDEF-UP, 1994. (tese de doutorado).

_. Crescimento, actividade física e aptidão física em países não industrializados: abordagem biocultural em crianças e jovens de Moçambique. Agon. Coimbra, n.2, p.86-102, 1995.

PULH, L \& NAHAS, M. V. Habilidades motoras em crianças de 10 a 12 anos de diferentes níveis sócio-econômicos em Florianópolis-SC. Revista Brasileira de Ciência e Movimento. São Caetano do Sul, v.3, n. 1, p.7-11, 1989.

ROSS, J. G. et al. The national children and youth fitness study II. Study procedures and quality control. JOPERD. p.54-62, 1987.

SALLIS et al. Determinants of physical activity and interventions in youth. Medicine and Science is Sport and Exercise. v.24, p.s248-s257, 1992.

-. Physycal activity assessment methodology in the five-city project. American Journal of Epidemiology. v. 121, p.91 -106. 1985.

SIMONS, J. et al. Health-related physical fitness in chilhood. Status and recommendations. Annual Rewiew of Public Health. v.9, p.403-425, 1988.

SOBRAL, F. Estatísticas e normas antropométricas e de valor fisico. Lisboa: S.R.E.C/UTL, 1986.

_. Estado de crescimento e apti dão física na população esco lar dos Açores. Lisboa : SRECEFD.RAA/ISEF-UTL, 1989.

SOBRAL, F. ; MARQUES, A. T. FCDEX. Desenvolvimento somato-motor e factores de excelência desportiva na população escolar portuguesa. Lisboa : Ministério de Educação. Gabinete Coordenador do Desporto Escolar, 1991. v.2
TORRES, L. Hábitos de vida de alunos de uma escola da rede municipal de ensino de Porto Alegre. Revista Perfil. Porto Alegre, v.l.n.1, 1997.

VACCARO, P. \& MAHON, A. D. The effects of exercise on coronary heart disease risk factors in children. Sports Medicine, v.8, p.139-153, 1989.

VAGO, Tarcísio . O "esporte na escola" e o "esporte da escola": da negação radical para uma relação de tensão permanente Um diálogo com Valter Bracht. Revista Movimento. Porto Alegre, v.3, n.5, p.4, 1966/2.

\section{NOTA}

${ }^{1}$ AHHAPERD, 1976, 1980, 1988; EUROFIT, 1990; Cureton, 1987; Simons-Morton et al., 1988; Vaccaro

\&Mahon, 1989; Kuntzleman \& Reiff, 1992. Especialmente nos paí ses de língua portuguesa, Sobral, 1986, 1989, 1991; Prista, 1994; Marques, 1988; Freitas et al., 1997; Pereira, 1996 (em Portugal) e Gue des, 1994; Guedes \& Barbanti, 1985; Matsudo, 1993 (no Brasil).

${ }^{2}$ Gaya \& Torres, 1997; Torres, 1997; Sallis \& Sallis, 1992; Malina, 1988; Kalinowski, 1995; Ferreira et al, 1990; Cunha, 1985; Negrão, 1981; Anjos \& Boileau, 1988; Pulh \& Nahas, 1989.

${ }^{3}$ Gaya, 1989; Guedes \& Guedes, 1993, 1994; Devide, 1996; Faria Jr.,1991; Farinatti, 1995; Bento, 1991, 1989.

${ }^{4}$ PRODESP, sigla de Projeto Des porto, configura-se num amplo projeto de investigação no âmbito da pedagogia do desporto referenciado à promoção da saúde ou à detecção de talentos desportivos levado a cabo pelo Centro de Excelência Esporti vo da Escola de Educação Física da UFRGS e do INDESP. O projeto tem como coordenador geral o primeiro autor do presente artigo.

${ }^{5}$ Para provas de natureza psicomotora, segundo Nunnally (1978), considera-se como valor empírico de corte $u m r=0.70$

${ }^{6}$ Outliers representam valores supe riores ou inferiores ao escore $3 \mathrm{Z}$ ou 3 desvios padrão.

${ }^{7} \mathrm{O}$ teste de Duncan é um teste post hoc menos conservador, ou seja, em relação a outros testes, tais como Tukey e Scheffé, por exemplo, ele maximiza o erro do tipo 1 - rejeitar a hipótese nula quando ela é verdadeira. Isso significa, em outras palavras, a possibilidade de detectar diferenças onde elas não ocorrem. Todavia, no presente estudo, consideramos mais adequado aceitar a possibilidade desse tipo de erro do que aceitar a possibilidade de erro do tipo 2 - aceitar a hipótese nula quando ela é falsa.

${ }^{8}$ Ver sobre esse tema o estudo de Prista (1995) com crianças moçambicanas - Subdesenvolvimento, crescimento, aptidão física e ativida des físicas em países não industrializados. In. Agon, 2: 85-102.

${ }^{9}$ Cf. Duarte et al, 1997.

${ }^{10}$ Cf. Pereira, 1996.

${ }^{11}$ Cf. Prista, 1994.

${ }^{12}$ Cf. Matsudo, 1996.

${ }^{13}$ Cf. Sobral et al, 1992.

${ }^{14}$ Cf. Sobral, 1986 e 1989.

${ }^{15} \mathrm{Cf}$. Mechelen et al. (apud Duarte, 1997).

${ }^{16}$ Cabe ressaltar que, na bateria PRODESP, o ponto correspondente ao nível dos pés na caixa de Wells corresponde ao índice de $15 \mathrm{~cm}$. Nos

gráficos comparativos entre amos tras, sempre que foi possível detectar o uso de escalas distintas (como $23 \mathrm{~cm}$ sugeridas pela AAPHERDou $30 \mathrm{~cm}$ como sugere a NCYFS) corri gimos os dados para adequar as comparações.

${ }^{17}$ Cf. Guedes, 1994.

${ }^{18}$ Cf. Duarte et al, 1997.

${ }^{19}$ Cf. Pereira, 1996.

${ }^{20}$ Cf. Prista, 1994.

${ }^{21}$ Cf. Ross e Pate, 1987.

22 Cf. Van Mechelen et al. (apud Duarte, 1977).

${ }^{23}$ Cf. Ostyn et al., 1980.

${ }^{24}$ Cf. Marques et al., 1992.

${ }^{25} \mathrm{O}$ valor de $17 \mathrm{~cm}$ está corrigido para comparação com nossos dados. O original é $25 \mathrm{~cm}$, partindo dos crité rios da AAPHRD cujo o ponto de intersecção entre a ponta dos pés e as mãos é $23 \mathrm{~cm}$.

${ }^{26}$ Para as variáveis velocidade de des locamento e resistência de longa duração, tendo em vista a adoção de 
metodologias distintas, não apresentamos os estudos comparativos com as outras amostras referenciadas neste estudo. Poderíamos realizar as comparções através da velocidade média percorrida em cada percurso, no entanto não o fizemos por entender que esse índice não seria consistente para os dois testes.

${ }^{27}$ Ver nota 26

${ }^{28}$ Como os testes são distintos, ado tamos, como forma de comparação, a velocidade média de corrida.

${ }^{29}$ Com exceção para os rapazes, das comparações entre 9 e 10,14 e 15 anos e para as moças, excetuando as comparações entre 7 e $8 ; 8$ e 9; 11 e $12 ; 13$ e $14 ; 14$ e 15 anos.

${ }^{30} \mathrm{Na}$ secção seguinte, apresentare mos mais detalhes sobre o qudro referencial de aptidão física para saúde proposto por Cooper.

${ }^{31}$ Rowland, 1990, apud Prista, 1994, p.5.

${ }^{32}$ Carpersen, C. J. et al Physical activity, exercise and physical fitness: definitions and distinctions for health-related research. Public Health Reports, 100, 126-130, 1985.

${ }^{33}$ Como, por exemplo, a adoção da Análise Fatorial, Análise de Traje tória, LISREL, etc.

${ }^{34}$ Ver Cooper, K. Saúde e boa for ma para seu filho. Nórdica, Rio de Janeiro, 1991, p.113-114.

${ }^{35}$ Como os testes são distintos, ado tamos como forma de comparação a velocidade média de corrida.

${ }^{36}$ Almond, L. El ejercicio físico y salud en la escuela. In. Devis, J. J \& Velert, C. P. Nuevas perspecti vas curriculares en educación física. Barcelona, INDE, 1992, p. 47-55.

\section{UNITERMOS}

Pedagogia do desporto - educação física - educação física e saúde.

*Adroaldo Gaya é professor do Departamento do Desporto e do Mestrado em Ciências do Movimento Humano da UFRGS. Doutor em Ciências do Desporto.

* Marcelo Cardoso é professor da Secretaria Estadual de Educação-RS. Mestrando em Ciências do Movimento Humano da UFRGS.

Osvaldo Siqueira é professor de Educação Física. Mestrando em Ciências do Movimento Humano da UFRGS

Lisiane Torres é professora da Rede Municipal de Ensino de Porto Alegre. Mestranda em Ciências do Movimento Humano da UFRGS. 